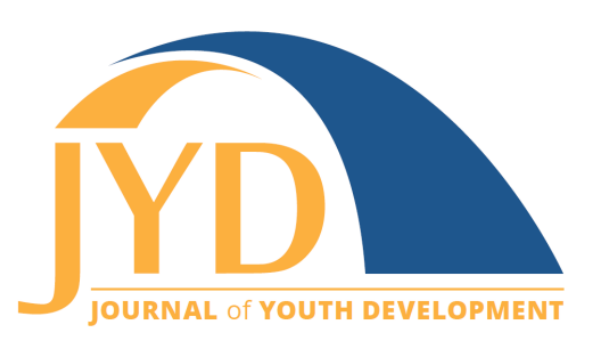

http://jyd.pitt.edu/ | Vol. 16 Issue 2-3 DOI 10.5195/jyd.2021.1025 | ISSN 2325-4017 (online)

\title{
Adolescent Well-Being Gap Maps: What We Know and Opportunities for Future Research
}

\author{
Prerna Banati \\ UNICEF \\ pbanati@unicef.org \\ Cristina Bacalso \\ Independent Consultant, Berlin, Germany
}

\begin{abstract}
Designing and delivering effective programs for adolescents and youth requires high-quality evidence that is easily available to decision makers. Yet while adolescence as a unique development period has gained policy attention in recent years, and there has been a growth in research, priorities for research investment remain unclear. This paper provides a panoramic view of adolescent development research to review what evidence exists and how evidence is mapped. Our approach interrogated studies mapped by evidence maps (including the subset evidence gap maps or EGMS). Our findings have implications for future directions of research on positive youth development (PYD) in low-and middle-income countries (LMICS): The analysis showed that while most evidence maps exist in the adolescent protection, safety, and security domain, most studies focus on outcomes related to well-being and social and emotional health. There are gaps in demographic groupings and contexts studied. For example, while gender and sex inequities were the most prevalent in the studies identified, though seen in less than 1/5 of the studies analyzed, disability appears in only 3\%. Housing, participation, and information communication technologies are researched relatively rarely. Rigorous research in conflict or humanitarian settings is absent. Additionally, while most impact evaluations are conducted in sub-Saharan Africa, followed by Latin America, the Middle East and North America were poorly represented regions. This article reflects on the state of the evidence, argues for a more thoughtful approach to equity in adolescent research, and calls for a stronger link between research, policy, and practice in LMICs.
\end{abstract}

Key words: evidence map, adolescent, equity, systematic reviews, impact evaluations

\section{Background}

Understanding what works to improve adolescent wellbeing is integral to the development of effective policies and programs to meet global commitments of the sustainable development

(cc) EY New articles in this journal are licensed under a Creative Commons Attribution 4.0 License. This journal is published by the University Library System, University of Pittsburgh and is cosponsored by the University of Pittsburgh Press. The Journal of Youth Development is the official peer-reviewed publication of the National Association of Extension 4-H Youth Development Professionals and the National AfterSchool Association. 


\section{Adolescent Well-Being Gap Maps}

goals (SDGs). Since the launch of the SDGs in 2015, the policy and practice community has rallied around adolescence as a critical phase in life for achieving human potential and ultimately these societal goals. However, there has been an historical context of a lack of systematic research investment to inform the policy and programs aimed at achieving the SDG indicators, targets and goals related to the healthy development of youth. High-quality evidence is required and must be made readily available to practice, program, and policy audiences, and mapped in a way that enables uptake and use.

In the last 40 years, specialized journals addressing the development of adolescents have been launched, including the Journal of Adolescent Health, Journal of Adolescence, the Journal of Adolescent Research, the Journal of Research on Adolescence, and the Lancet Child \& Adolescent Health (Lansford \& Banati, 2018). More recently, there has been a call for more nuanced and more relevant evidence to fill gaps in the adolescent research landscape. The growth of high-quality evidence on positive youth development (PYD), largely in high income developed contexts, has been an important contribution to filling this gap (see YouthPower, 2017; Lerner et al., 2018). The Lancet Commission on Adolescent Health and Wellbeing (2016) states: "In general, there is a need to better understand what works for males and females, for different age groups of adolescents and for socially marginalized groups" (Patton et al., 2016, p. 2470). The National Academy of Sciences, Engineering and Medicine (2019) concludes that a substantial proportion of research categorizes adolescents in "fairly gross ways" such as by applying gender but not by sexual orientation. Bornstein (2017) articulates the Specificity principle, noting that research hypotheses can be more adequately tested, inconsistencies and discrepancies in literature can be satisfactorily resolved, interventions can be tailored to be more successful, and policies can achieve effectiveness if research recognizes specific setting conditions of specific populations (including age groups) at specific times in history.

The National Academic of Sciences, Engineering and Medicine (2019) also note that adolescent research tends to focus on problem behaviors, rather than positive indicators of adolescent and youth development (seen in PYD). Lansford \& Banati (2018) state that "further research is needed on challenges and opportunities of multisectoral programs for adolescents" and note the absence of research "studying adolescent civic and social participation and engagement" (p.463).

This paper seeks to take stock of the state of policy and practice-relevant evidence on adolescent well-being. By interrogating impact evaluations and systematic reviews (from now on called "studies") mapped by tools called evidence maps (including the subset evidence gap maps or EGMs), we can understand where we have invested in evidence and where we have 


\section{Adolescent Well-Being Gap Maps}

failed to invest. The evidence is usually mapped to a framework in terms of the types of programs evaluated and the outcomes measured. By looking at the gaps in evidence across this framework, we make a case for where investments in evidence for action on adolescent development should be focused in the years to come.

Broadly speaking, evidence mapping involves identifying and collating evidence in a particular sector or subsector, with the aim to facilitate informed judgement and evidence-based decision making. Various approaches to evidence mapping exist, with a range of methodologies that differ depending on their aim; scope; type of evidence included; and the comprehensiveness of their search, data extraction, and analysis (Snilstveit et al., 2013). Using evidence maps as an entry-point to the landscape of evidence, we sought to understand what evidence on adolescent development is mapped for use by policymakers; how evidence is mapped; and what evidence exists. An example protocol of a typical evidence map can be found in the Appendix.

A number of efforts contribute to our understanding of what adolescent research exists, and what gaps remain. The Lancet Commission on adolescent health and well-being (2016) and other volumes (Lansford \& Banati, 2018; National Academies of Sciences, Engineering, and Medicine, 2019) have undertaken extensive reviews of existing literature, and there have been a series of high-quality systematic reviews and meta-reviews that have been conducted in selected domains (Patton \& Temmerman, 2016; Salam et al., 2016a; 2016b). In response to practitioner demand, in recent years, several evidence maps have explicitly focused on adolescents across different domains of their well-being, including sexual and reproductive health (Rankin et al., 2016); education (International Initiative for Impact Evaluation, 2015); transferrable skills (Rankin et al., 2015); participation and agency (Marcus \& Cunningham, 2016); protection, participation, and financial and material well-being (Bakrania et al., 2018).

Our analysis undertakes meta-level analyses of these multi-dimensional and multi-outcome gap maps and is based on eight outcome domains of adolescent well-being which are consistent with the Sustainable Development Goals. This assures a high degree of coherence between our analysis and actionable policy and program-relevant evidence gaps. The analysis also interrogates questions of equity, including how these dimensions are captured in current maps, and what might be needed to advance how we capture inequities in future mapping efforts. 


\section{Adolescent Well-Being Gap Maps}

\section{Methodology}

\section{Step 1: Identifying Maps for Inclusion}

We systematically included evidence maps published on or after the year 2003, which is the earliest year that such maps were identified (Saran \& White, 2018), until May 2019. Only completed maps were included in the analysis. No geographic constraints were applied, though we observed that to date maps have largely been employed by the international development community, and hence most were focused on low- and middle-income contexts.

To be included in the analysis, an evidence map needed to demonstrate acceptable methodology, including, for example, measures of intervention effectiveness on adolescent wellbeing outcomes, a causal chain or similar logic of causality linking interventions to outcomes, and clear inclusion criteria.

The primary population of interest for this paper is adolescents. Even when the target population of an evidence map is not adolescents, adolescents can nevertheless be included within the scope of a map; for example, defined as part of an outcome or intervention component, or defined as a filter population by which studies can be disaggregated. While UNICEF and the World Health Organization (WHO) define an adolescent as a person between 10 and 19 years, and others have expanded analyses on adolescents to include youth up to 24 years (Patton \& Temmerman, 2016; Patton et al., 2016), the UNICEF EGM on adolescent wellbeing notes that data in impact evaluations are often not disaggregated in this way (Bakrania et al., 2018). As a result, evidence on adolescents can be scattered-across various domains, among different evidence maps, and also may be subsumed within other population categories (such as "youth").

For the purpose of this review, the target population included adolescents aged 10 to 19 , and populations that overlap with this age range, including "children," "youth," "teenagers," "students," "boys," and "girls." Maps that explicitly focus only on children under 10 years, or adults over 18 years, were excluded.

Figure 1 shows a visual representation of our process for identifying maps to be included in the study. A full list of maps can be found in the Appendix. 
Figure 1. Process for Identifying Maps

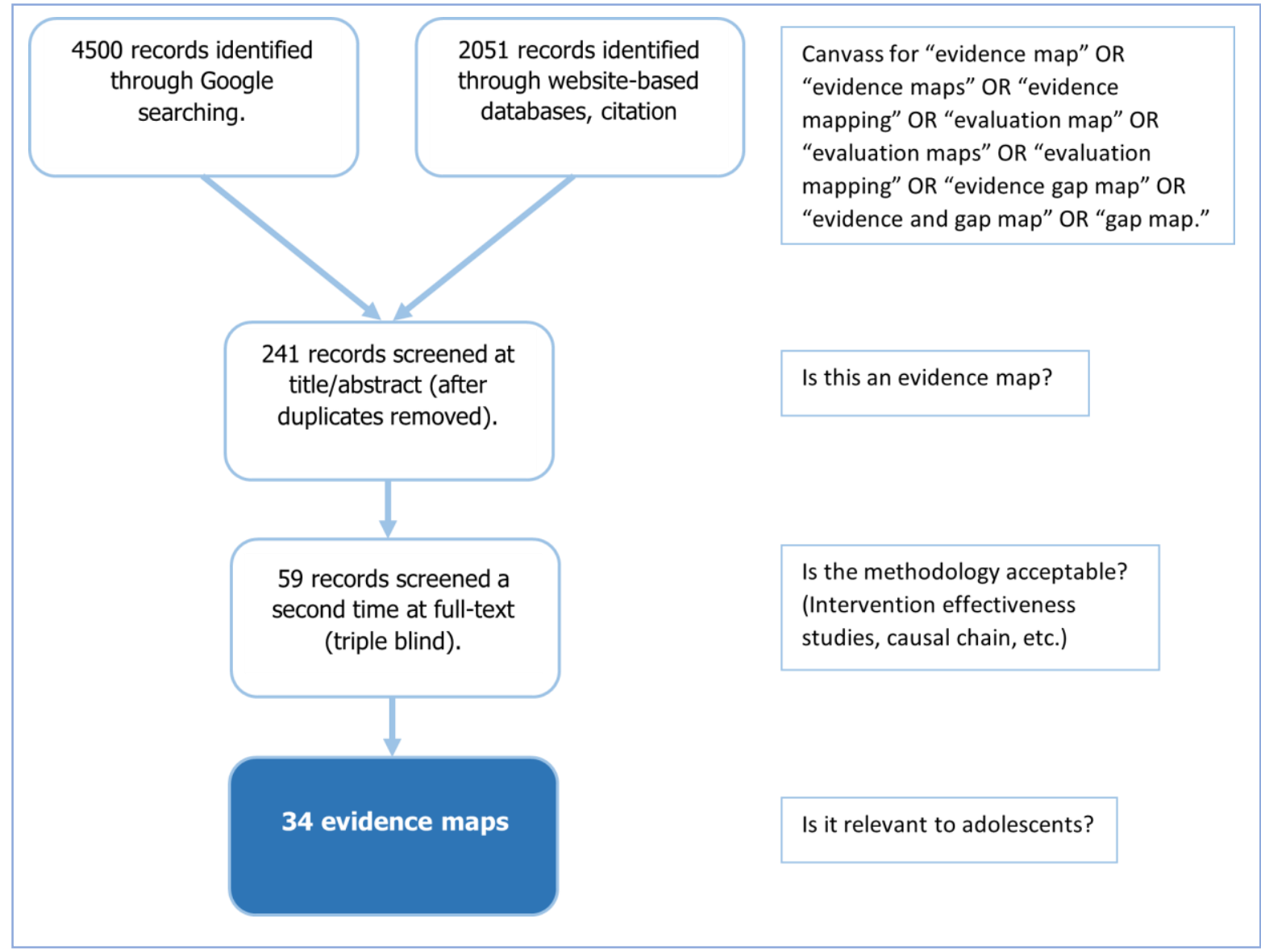

\section{Step 2: Screening Studies}

From the evidence maps that were screened for inclusion, the studies contained within them were also screened. The flow chart in Figure 2 gives a visual summary of the screening process.

At the study level, a study needed to have relevance to adolescents (similar to the map level above) and an acceptable study type, meaning only studies that are explicitly impact evaluations or systematic reviews were included. For impact evaluations, the studies had to use an experimental (i.e., randomized control trial, or RCT) or quasi-experimental (which also test causal hypotheses but may also lack random assignment [Snilstveit et al., 2013]) design, or mixed method study that incorporates one of the designs in its approach. In the assessment of studies, non-intervention study types (which included observational studies, or toolkits, for example) were excluded. At this stage 135 studies with non-experimental study designs were excluded from the analysis. 
Figure 2. Process for Screening the Studies (Impact Evaluations and Systematic Reviews) Contained Within the Evidence Maps

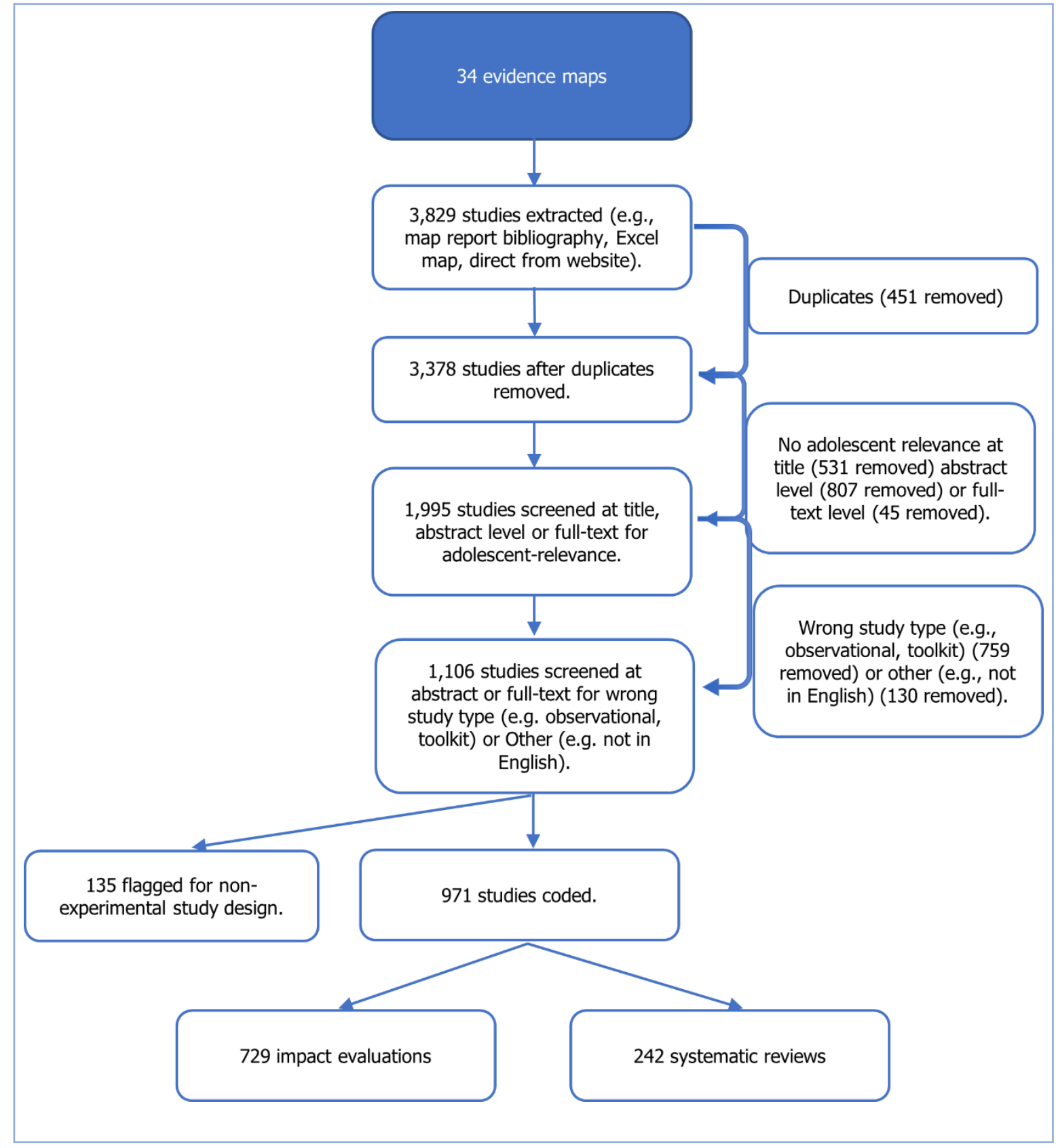

Step 3: Extracting Data From Studies

In order to categorize the data at the study level, key outcome domains of adolescent wellbeing (that are consistent PYD) were identified that are aligned with the Sustainable Development Goals (SDGs). 


\section{Adolescent Well-Being Gap Maps}

We reviewed a number of adolescent and youth indices and frameworks (e.g., Youth Development Index [Commonwealth Secretariat, 2016], UNICEF's Second Decade Program guidance [UNICEF, 2018]) and identified the following eight outcome domains: Economic and financial well-being; Empowerment and participation; Health and well-being; Housing; Information and Communications Technologies (ICT); Protection, safety and security; crosscutting domain (which includes interventions that could be relevant to all seven other domains, or conversely could not be associated with one domain in particular). These domains frame the analysis in the study, and the findings. They are selected for their broad applicability in various contexts and countries, alignment with the Sustainable Development Goals (SDGs) and, given their usage in well-known adolescent and youth indices, aimed to be easily recognizable and understood by policy audiences. Full descriptions of the domains can be found in the Appendix.

Employing an adapted PROGRESS-Plus framework (Welch et al., 2019), studies were also coded for their equity focus, including age (e.g., younger adolescents, older adolescents), caste, disability, education, gender and sex, occupation/employment status, place of residence, race, ethnicity, culture, language, religion, sexual orientation, social capital, socioeconomic status, and other. Equity factors are described as those that may stratify and drive variations in wellbeing outcomes (O'Neill et al., 2014). Definitions for each dimension (adapted from Oliver et al., 2008), and coding criteria can be found in the Appendix.

Specific age categories were coded, when possible: under 10 (less than 10 years old), early adolescence (10 to 12 years old), middle adolescence (13 to 15 years old), late adolescence (16 to 19 years old), and young people over 20 (20 years and older). When a population overlapped several categories, more than one could be selected. For example, an impact evaluation assessing an intervention aimed at participants aged 15-24 years would be coded for middle adolescence, late adolescence, and young people over 20.

The socio-ecological sphere or level of focus was also coded. Those at the micro level include a focus at the individual and interpersonal level (e.g., literacy rates), including outcomes of individuals and at the household level, including family. Meso level encompasses the group and community level, and includes outcomes in schools, clubs, cooperatives, or community groups, but which bear specifically on adolescent well-being outcomes (e.g., social norms, attitudes towards adolescents). Those that were coded as macro encompass outcomes at the policy and institutional level and include programs and policies designed to have an influence on the macro environment and policy contexts for adolescents (e.g., adolescent reproductive health policy; Bakrania, Ghimire, \& Balvin, 2018). 


\section{Adolescent Well-Being Gap Maps}

Context beyond geographic regions, for example humanitarian, conflict, post-conflict, urban, and rural, were also captured, when the author identified one (or more) of these features as important to the focus of the study.

\section{Findings}

We completed analysis across the eight domains at three levels: the map level reviewed maps themselves $(n=34)$, the outcome component level analyzed the outcomes captured in each map ( $n=560)$; the study level analyzed each study that formed part of any map $(n=971)$. Findings relating to the study level are presented below. The methodology and findings relating to the map and outcome component levels are available in the Appendix.

\section{Study Level Findings}

"Adolescents" can be found across a wide range of age labels, as seen in Figure 3. Most common among studies is for adolescents to be subsumed into the "children" category (28\%; 270/971 studies), while "adolescents" as a distinct category appears in $22 \%$ of studies (214/971 studies). This is followed closely by "students" (22\%; 212/971 studies), then "youth" (15\%; 144/971 studies). Figure 4 shows the age-range focus of studies. Middle adolescence (13 to 15 years old) remains the most studied (37\%; 364/971 studies), followed closely by late adolescence (16 to 19 years old) (33\%; 324/971 studies) and then early (10 to 12 years old) (29\%; 286/971 studies). 108 out of 971 studies (11\%) focus on adolescence (10 to 19 years old) specifically, or some part thereof, with 15 systematic reviews exclusively devoted to this age range. 
Journal of Youth Development | http://jyd.pitt.edu/ | Vol. 16 Issue 2-3 DOI 10.5195/jyd.2021.1025

Adolescent Well-Being Gap Maps

\section{Figure 3. Age Label Employed by Studies}

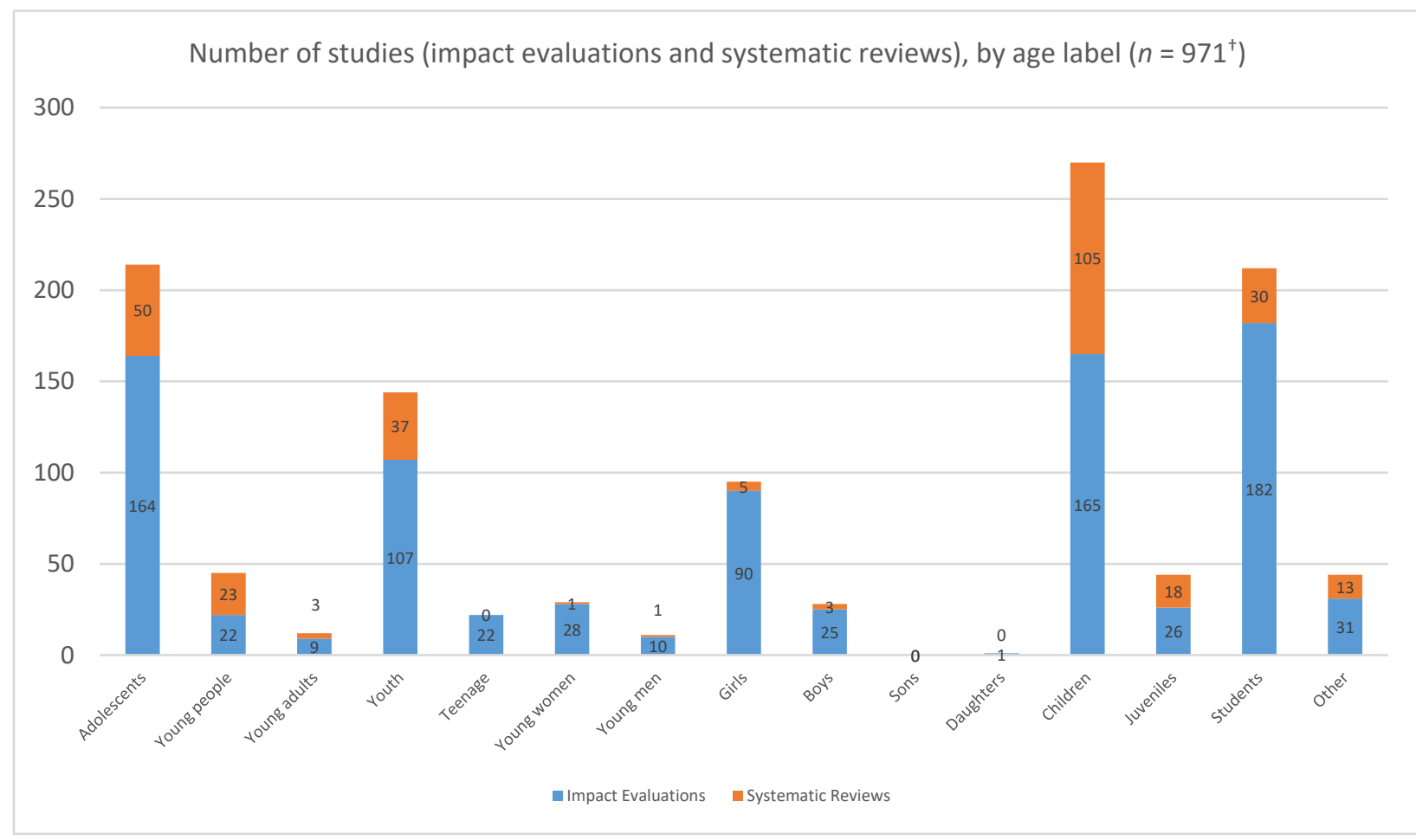

Note. ${ }^{\dagger}$ Double counting possible.

Figure 4. Age Focus of Studies

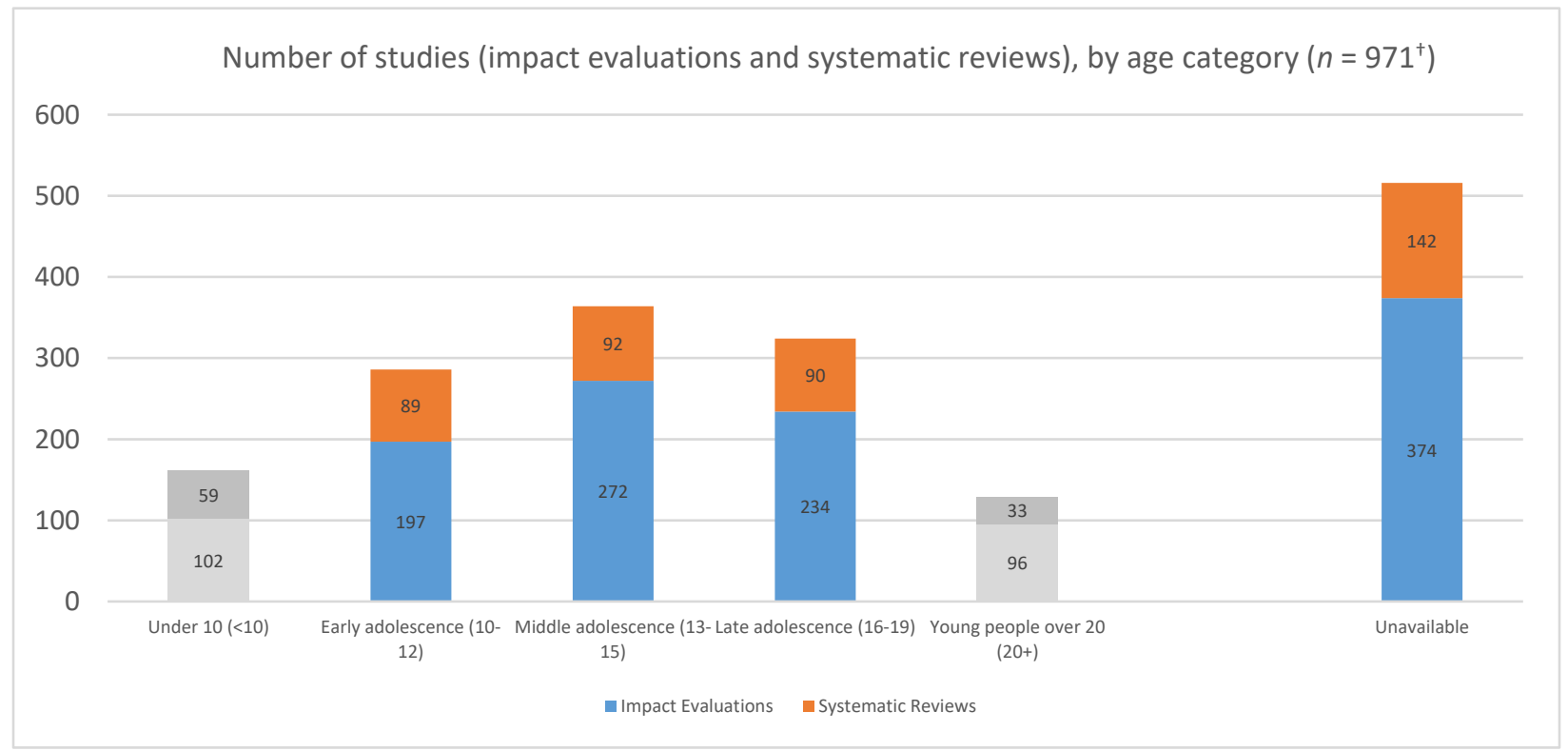

Note. ${ }^{\dagger}$ Double counting possible. 


\section{Adolescent Well-Being Gap Maps}

Findings regarding the socio-ecological level of intervention show that a substantial number of studies focus on the micro level (85\%; 825/971 studies), far fewer on the meso level (18\%; $175 / 971$ studies), and only $2 \%$ of studies (24/971 studies) focus on the macro. This pattern similarly applied whether we were looking at systematic reviews or impact evaluations.

Figure 5 shows the geographic distribution of impact evaluations, which make up three-quarters of all studies included (729/971 studies). Most impact evaluations are conducted in sub-Saharan Africa (33\%; 238/729 impact evaluations), with $15 \%$ of impact evaluations (108/729 impact evaluations) observed in Latin America. Given that only English language maps and studies were included in analysis, this number is likely to be underestimated. With only $4 \%$ of impact evaluations in both (31/729 impact evaluations each), Middle East and North America were poorly represented regions for impact evaluations. Low numbers in North America, in particular, can be in part explained by the low numbers of evidence maps focused on high-income countries overall.

\section{Figure 5. Geographic Focus of Impact Evaluations}

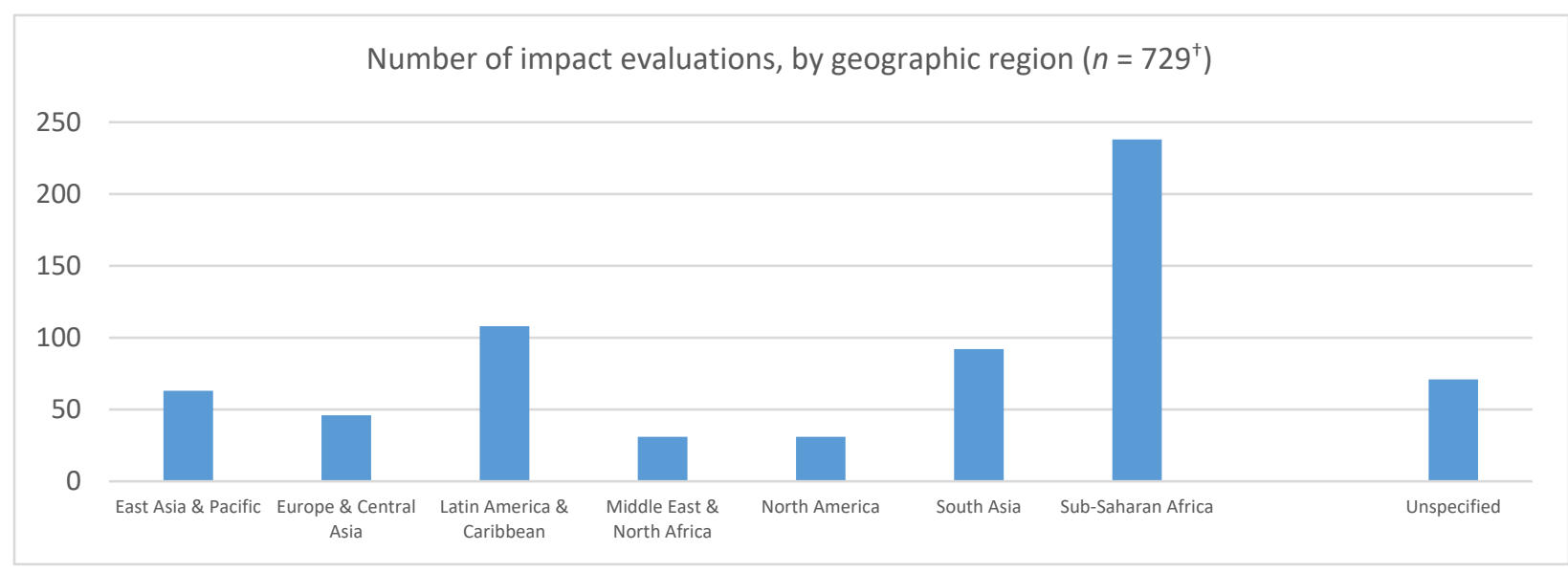

Note. ${ }^{\dagger}$ Double counting possible.

While evidence maps on protection are most common, it is the domain of health (50\%; $488 / 971$ studies) followed by education ( $46 \%$; $448 / 971$ studies) that are the most common at the study level. On the other hand, the empowerment and participation domain makes up only $7 \%$ of studies (65/971 studies), cross-cutting in $2 \%$ of studies (22/971 studies), and only one study (an impact evaluation) is coded for housing. The distribution of domains at the study level is shown in Figure 6. 


\section{Figure 6. Domain Focus of Studies}

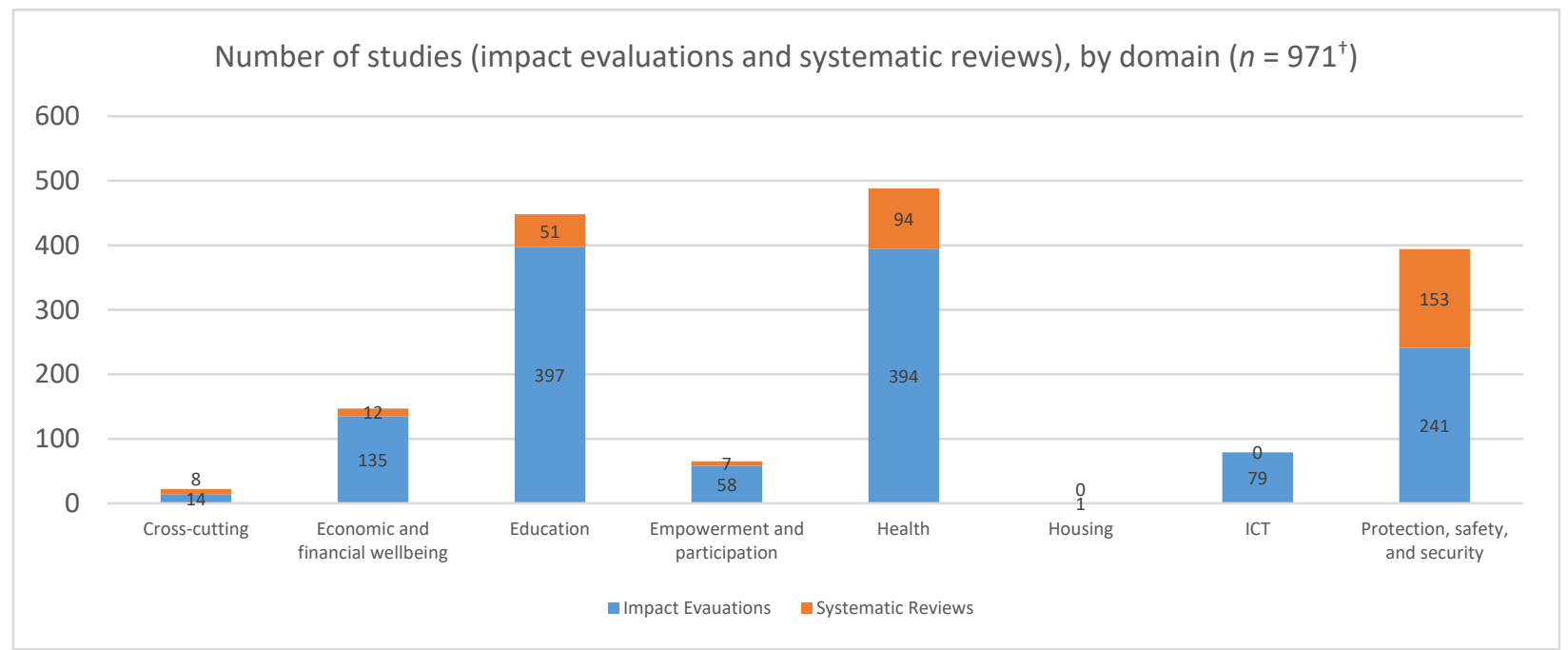

Note. ${ }^{\dagger}$ Double counting possible.

There was some consideration of equity in $53 \%$ of studies (517/971 studies), whether it was assessing the effects of interventions targeting disadvantaged populations, assessing interventions aimed at reducing social gradients, or assessing effects of an intervention targeted at the general population but explored variations in outcomes across a PROGRESS-Plus characteristic (full coding framework in the Appendix). We faced challenges however in employing the adapted PROGRESS-Plus definition at the study level. For example, we noted a lack of specification as to whether the intention to target a disadvantaged group through a specific intervention sought to reduce inequality. It was also challenging to understand whether vulnerability was defined by mutable or immutable characteristics. The most common equity category was "Other" (26\%; 255/971 studies), which included dimensions such as HIV status, PTSD symptoms, and experience as a former child soldier. Gender and sex were the next most common (18\%; 179/971 studies) followed by socioeconomic status (11\%; 110/971 studies). Only $3 \%$ of studies (29/971 studies) focused on disabilities, as shown in Figure 7. 


\section{Figure 7. Equity Dimensions Included in Studies}

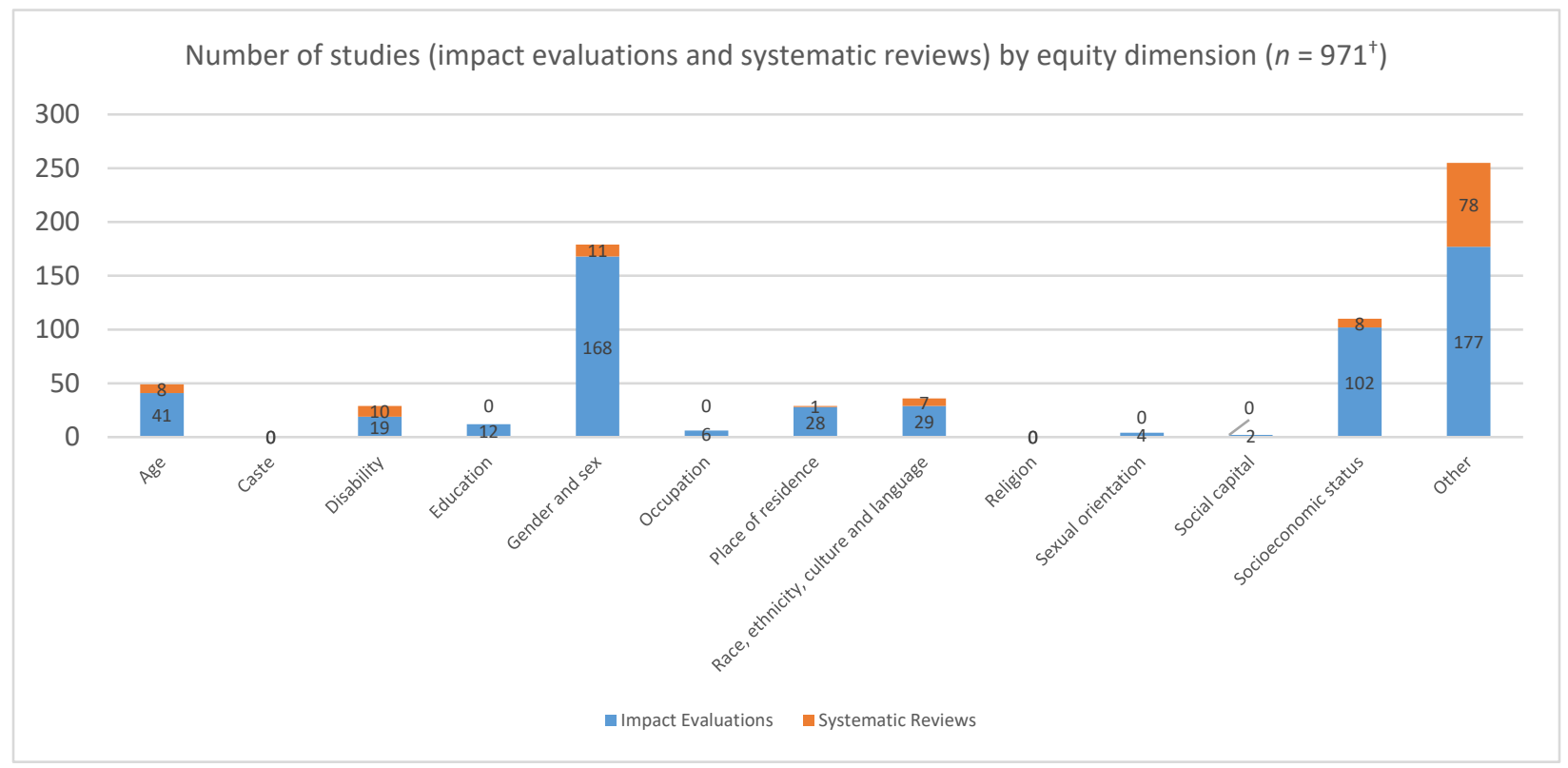

Note. 'Double counting possible.

\section{Conclusion}

The aim of this analysis is to push coherence around outcomes for adolescent and youth development and to understand pathways to achieving these outcomes, in order to guide sectoral policy and program planning, and capture interventions that may target multiple outcomes at one time. We looked across a wide range of outcomes to review what evidence is mapped for use by policymakers, how evidence is mapped, and what evidence exists.

How research engages with the questions of equity amongst adolescents is a key concern. Given the potential for this age group to break intergenerational cycles of disadvantage-and that equity in almost every domain and context is a human right-a more thoughtful approach to introducing equity considerations into research about youth in this age group is needed.

Moreover, evidence maps that allow the user to employ more age-specific filters could make retrieving studies easier and add complexity to the outcome/intervention frameworks they use. For example, a filter for studies relating to children or adolescents would be helpful for maps that do not target these groups (for example, the International Rescue Committee's Cash Transfer Map or Safety Map), or for adolescent-focused maps, a filter for early, middle, and late adolescence (as is used in the UNICEF 2018 evidence map) would illuminate the areas of 


\section{Adolescent Well-Being Gap Maps}

evidence coverage and gaps even further. Similarly, this could extend to filters by equity dimension, and context.

\section{Key Findings}

- Most evidence maps exist in the protection, safety and security domain, while most evidence exists in health.

- Our analysis clearly identified outcome domains that appear to have been relatively underinvested in terms of research-housing, participation, and ICT presented the most gaps. This may reflect a lack of quality research studies (which may not be amenable to synthesis), a lack of methodological applicability (we focused only on systematic reviews and impact evaluations), or a need to encourage the use of gap map methodology across these domains.

- The relative absence of rigorous research in conflict or humanitarian settings (relative to development settings) suggests an important gap needs to be filled. Few studies grappled meaningfully with the developmental science and contextual specificities of the unique window of adolescence and early youth.

- In our analysis on inequities, gender and sex inequities were the most prevalent observed, though seen in only less than one-fifth of studies. Disability appears in only $3 \%$ of impact evaluations or systematic reviews (29/517 studies.

- We noted that most impact evaluations are conducted in sub-Saharan Africa, followed by Latin America. Both the Middle East and North America were poorly represented regions for impact evaluations. This means these methods were not used as extensively to determine what works for adolescents and youth in these regions.

\section{Discussion}

Reflecting on the domains for this analysis, relative to the health or education sectors, scientific discourse, and scholarly literature in fields such as housing and ICT is in infancy, at least in LMICs. Given multiple and intersecting vulnerabilities that impact adolescents (Patton et al., 2014), and recognizing that domains may interact (Viner et al., 2012), filling the evidence gap across all domains, particularly those that are underserved, remains a priority and much needed to advance the integrated vision of the SDGs. Findings from analysis of the health domain suggest that research uptake and use can be significantly impacted with a continued effort to map and consolidate the evidence base related to adolescent and youth health outcomes. This 


\section{Adolescent Well-Being Gap Maps}

can improve efficiency of research investments and also extend the reach of their findings to practice audiences.

In a number of areas, where youth vulnerability is high (and policy attention equally so) such as in youth involvement in peacebuilding (United Nations Security Council, 2018, 2020), better understanding is needed of how young people themselves can benefit from such interventions for their own well-being, how they contribute to individual and societal resilience, and equally how such interventions might benefit from their participation.

While it may be cost-effective to capture a wide range of ages within one systematic review or impact evaluation, we believe adolescent and youth research may benefit from age-sensitive methodologies that respond to the unique needs of this period of life. At the same time, it is important that studies attempt to disaggregate findings by younger (10 to 14) and older age groupings, so as to be most informative for program audiences.

Our analysis on inequalities pointed to the absence of robust and readily useable frameworks that assess and capture different forms of inequalities among this group. To assess inequalities, the PROGRESS-Plus framework was useful, but we observed many challenges. Given that the adolescent years are when we see inequalities becoming entrenched and solidifying (often for life), and the important emphasis the Sustainable Development Goals (SDGs) place on reducing inequalities, a greater focus is needed. Improved methodologies and frameworks that can be easily employed would take such analyses a step forward. Critically, greater investments are needed to advance research of inequities among adolescents.

Finally, our findings point to the need for the future of adolescent and youth research to engage more with questions of external validity and transportability of interventions across settings, recognizing the need for contextualized program interventions for adolescents. Systematic reviews that assess the degree to which interventions can be adopted in different geographical contexts from where they were designed would be a useful addition to the evidence base.

\section{Limitations}

This analysis focused on a subset of research on adolescent well-being: those that are in the peer-reviewed literature and amenable to synthesis or mapping. We excluded non-English maps and studies (impact evaluations and systematic reviews) in the analysis, which may have implications for geographic distribution. However, based on our review we estimate that there are very few non-English-language evidence maps that exist. 


\section{Adolescent Well-Being Gap Maps}

This analysis includes studies that have been included based on differing criteria for quality based on the map authors' criteria and estimation (see Appendix). While these might be diverse estimations, at the study level, our analysis included only systematic reviews and experimental/quasi-experimental impact evaluations, which are considered some of the most robust evidence available to assess intervention effectiveness and is in keeping with the 3ie approach to evidence gap maps (Snilstveit et al., 2013), which is common to many maps. Ultimately, this approach will have resulted in the exclusion of some important bodies of evidence, for example, qualitative evaluations that use observational designs.

The search strategies employed were systematic-like in their approach, though cannot claim to be systematic searches. We used pre-defined search strings but concentrated on common website-based databases (International Initiative for Impact Evaluation \& The Centre of Excellence for Development, Impact and Learning, 2017) and by exhaustive search in Google. The full protocols are available in the Appendix.

Triple blind screening and independent double coding was employed at the map level. At the study level, single coding was employed. Double coding verification applied to $10 \%$ of the studies reviewed. Given the large number of studies reviewed, coding was undertaken at the abstract level and full text was used only when readily available. Thirty-five percent of studies were reviewed at full-text level.

Despite employing no geographical limitations, very few maps were identified from high-income settings. The evidence map methodology seems to be largely applied to low- and middleincome country settings. As a result, the findings are likely to be more robust when focused to this geographic area. We sought to code studies for context including humanitarian, conflict, post-conflict, and urban or rural. However only $15 \%$ of studies (150/971 studies coded identified context (beyond geography), and only $3 \%$ of studies (31/971 engaged in conflict settings. This limits our findings in these contexts.

\section{Acknowledgements}

This work was funded through the generous contribution of the U.K. Department of International Development to UNICEF's Office of Research at Innocenti's Social and Structural Determinants of Adolescent Wellbeing Research Program. 


\section{Adolescent Well-Being Gap Maps}

We acknowledge our steering committee members, Shivit Bakrania (UNICEF Innocenti, Italy), George Patton (University of Melbourne and Murdoch Children's Research Institute, Australia), Suzanne Petroni (Gender Equity Solutions, United States), and Sharlene Swartz (University of Cape Town and University of Fort Hare, South Africa), for providing valuable comments at regular intervals and strategic guidance for this paper.

\section{References}

Bakrania, S., Ghimire, A., \& Balvin, N. (2018). Bridging the gap to understand effective interventions for adolescent well-being: An evidence gap map on protection, participation, and financial and material well-being in low- and middle-income countries. UNICEF Office of Research - Innocenti, Florence.

Bornstein, M. H. (2017). The specificity principle in acculturation science. Perspectives on Psychological Science, 12(1), 2-45. https://doi.org/10.1177/1745691616655997

Commonwealth Secretariat. (2016). Global youth development index and report. The Commonwealth.

European Youth Forum, Deloitte, International Institute for Democracy and Electoral Assistance, Organisation for Security and Cooperation in Europe, \& Social Progress Imperative, and in collaboration with the International Organisation of Employers. (2017). Youth progress index. https://www.youthforum.org/youth-progress-index

International Initiative for Impact Evaluation. (2015). Youth \& transferable skills evidence gap map. International Initiative for Impact Evaluation. https://gapmaps.3ieimpact.org/evidencemaps/youth-transferable-skills-evidence-gap-map

International Initiative for Impact Evaluation \& The Centre of Excellence for Development, Impact and Learning. (2017). A map of evidence maps relating to lower-and middle income countries (Draft report). The Centre of Excellence for Development, Impact and Learning.

International Telecommunication Union. (2017). ICT facts and figures 2017. ICT Data and Statistics Division, International Telecommunication Union.

Lancet Commission. (2016, May 11). Our future: A Lancet commission on adolescent health and wellbeing. The Lancet. https://www.thelancet.com/commissions/adolescent-health-and-wellbeing

Lansford, J. E., \& Banati, P. (Eds.). (2018). Handbook of adolescent development research and its impact on global policy. Oxford University Press.

Lerner, R. M., Tirrell, J. M., Dowling, E. M., Geldhof, G. J., Gestsdóttir, S., Lerner, J. V., Ebstyne King, P., Williams, K., Iraheta, G., \& Sim, A. T. R. (2018). The end of the beginning: Evidence and absences studying PYD in a global context. Adolescent Research Review, 4, 1-14. https://doi.org/10.1007/s40894-018-0093-4 
Journal of Youth Development | http://jyd.pitt.edu/ | Vol. 16 Issue 2-3 DOI 10.5195/jyd.2021.1025

Adolescent Well-Being Gap Maps

Marcus, R., \& Cunningham, A. (2016). Young people as agents and advocates for development. Overseas Development Institute.

National Academies of Sciences, Engineering, and Medicine. (2019). The promise of adolescence: Realizing opportunity for all youth. (R. J. Bonnie, \& E. P. Backes, Eds.). The National Academies Press. https://doi.org/10.17226/25388

O'Neill, J., Tabish, H., Welch, V., Petticrew, M., Pottie, K., Clarke, M., Evans, T., Pardo, J., Waters, E., White, H., \& Tugwell, P. (2014). Applying an equity lens to interventions: using PROGRESS ensures consideration of socially stratifying factors to illuminate inequities in health. Journal of Clinical Epidemiology, 671), 56-64. https://doi.org/10.1016/j.jclinepi.2013.08.005

Oliver, S., Kavanagh, J., Caird, J., Lorenc, T., Oliver, K., Harden, A., Thomas, J., Greaves, A., \& Oakley, A. (2008). Health promotion, inequalities and young people's health: A systematic review of research. University of London, Social Science Research Unit, Institute of Education.

https://eppi.ioe.ac.uk/cms/Portals/0/PDF\%20reviews\%20and\%20summaries/Inequalities\%20You ng\%20People\%20R20080liver.pdf?ver=2010-12-22-123934-167

Patton, G. C., Ross, D. A., Santelli, J. S., Sawyer, S. M., Viner, R. M., \& Kleinert, S. (2014). Next steps for adolescent health: A Lancet commission. The Lancet, 383(9915), 385-386. https://doi.org/10.1016/S0140-6736(14)60039-8

Patton, G. C., Sawyer, S. M., Santelli, J. S., Ross, D. A., Afifi, R., Allen, N. B., Arora, M., Azzopardi, P., Baldwin, W., Bonell, C., Kakuma, R., Kennedy, E., Manon, J., McGovern, T., Mokdad, A. H., Patel, V., Petroni, S., Reavley, N., Taiwo, K., ... Viner, R. M. (2016, June 11). Our future: A Lancet commission on adolescent health and wellbeing. The Lancet, 38710036), 2423-2478. https://doi.org/10.1016/S0140-6736(16)00579-1

Patton, G., \& Temmerman, M. (2016, October). Interventions to address adolescent health and wellbeing: Current state of the evidence. Journal of Adolescent Health, 59 (4 Supplement), S1-S94. https://www.sciencedirect.com/journal/journal-of-adolescent-health/vol/59/issue/4/suppl/S

Rankin, K., Cameron, D. B., Ingraham, K., Mishra, A., Burke, J., Picon, M., Miranda, J., \& Brown, A. N. (2015). Youth and transferable skills: An evidence gap map (3ie Evidence Gap Map Report 2). International Initiative for Impact Evaluation. https://www.3ieimpact.org/evidencehub/publications/evidence-gap-maps/youth-and-transferable-skills-evidence-gap-map

Rankin, K., Jarvis-Thiébault, J., Pfeifer, N., Engelbert, M., Perng, J., Yoon, S., \& Heard, A. (2016). Adolescent sexual and reproductive health: An evidence gap map (3ie Evidence Gap Map Report 5). International Initiative for Impact Evaluation. https://www.3ieimpact.org/evidencehub/publications/evidence-gap-maps/adolescent-sexual-and-reproductive-health-evidence-gap

Salam, R. A., Das, J. K., Lassi, Z. S., \& Bhutta, Z. A. (2016a). Adolescent health and well-being: Background and methodology for review of potential interventions. Journal of Adolescent Health, 59(4 Supplement), S4-S10. https://doi.org/10.1016/j.jadohealth.2016.07.023 
Journal of Youth Development | http://jyd.pitt.edu/ | Vol. 16 Issue 2-3 DOI 10.5195/jyd.2021.1025

Adolescent Well-Being Gap Maps

Salam, R. A., Das, J. K., Lassi, Z. S., \& Bhutta, Z. A. (2016b). Adolescent health interventions: Conclusions, evidence gaps, and research priorities. Journal of Adolescent Health, $59(4$ Supplement), S88-S92. https://doi.org/10.1016/i.jadohealth.2016.05.006

Saran, A., \& White, H. (2018). Evidence and gap maps: A comparison of different approaches. Campbell Collaboration.

Snilstveit, B., Stevenson, J., Fenton Villar, P., Eyers, J., Harvey, C., Panfil, S., Puri, J., \& McKinnon, M. C. (2016). Land-use change and forestry programmes: Evidence on the effects on greenhouse gas emissions and food security (3ie Evidence Gap Map Report 3). International Initiative for Impact Evaluation.

Snilstveit, B., Vojtkova, M., Bhavsar, A., \& Gaarder, M. (2013). Evidence gap maps - A tool for promoting evidence-informed policy and prioritizing future research. Independent Evaluation Group, Public Sector Evaluation Department. The World Bank.

UNESCO Institute for Statistics. (2012). International standard classification of education: ISCED 2011. UNESCO.

UN-HABITAT. (2013). UN-HABITAT and youth. Office of the Secretary-General's Envoy on Youth. https://www.un.org/youthenvoy/2013/08/un-habitat-and-youth/

UNICEF. (2018). UNICEF Programme guidance for the second decade: Programming with and for adolescents. UNICEF.

United Nations Security Council. (2018). Resolution 2419 (2018). United Nations.

United Nations Security Council. (2020). Resolution 2535 (2020). United Nations.

Viner, R. M., Ozer, E. M., Denny, S., Marmot, M., Resnick, M., Fatusi, A., \& Currie, C. (2012). Adolescence and the social determinants of health. The Lancet, 379(9826), 1641-1652.

Welch, V. A., Petkovic, J., Jull, J., Hartling, L., Klassen, T., Kristjansson, E., Pardo, J., Petticrew, M., Stott, D. J., Thomson, D., Ueffing, E., Williams, K., Young, C., \& Tugwell, P. (2019). Chapter 16: Equity and specific populations. In J. P. T. Higgins, J. Thomas, J. Chandler, M. Cumpston, T. Li, M. J. Page, \& V. A. Welch (Eds.), Cochrane Handbook for Systematic Reviews of Interventions version 6.0. Cochrane.

YouthPower Learning. (2017). A systematic review of positive youth development programs in low- and middle-income countries. Making Cents International. 


\section{Appendix}

\section{Typical Protocol for Evidence Maps}

\section{Figure A1. Typical Protocol for an Evidence Map}

\section{Develop scope}

- Develop framework of interventions and outcomes structured along the causal chain.

- Can involve reviewing key policy documents and other literature, consulting with key stakeholders, or using existing frameworks (e.g., an organisational strategic plan)

\section{Set inclusion criteria}

- $\quad$ Determine types of evidence to be included, using the framework selected in the scope to set substantive inclusion criteria.

- Maps concerned with intervention effectiveness should include impact evaluations (experimental \&/or quasi-experimental; uses counterfactual analysis) or systematic reviews of such studies.

\section{Search for relevant studies}

- $\quad$ Search for studies that meet the inclusion criteria, drawing on systematic searching methods used for systematic reviews.

- While search methods should be as comprehensive as possible, they can be adapted depending on time and resources available and intended use of map.

\section{Assess for inclusion}

- Screen studies against substantive and methodological inclusion criteria set above.

Data extraction (and critical appraisal, if applicable)

- Systematically code and extract data using a structured format, according to relevant intervention and outcome categories used in the framework, and other relevant categories (e.g., study design, geography).

- $\quad$ Some maps also critically appraise quality of systematic reviews using a standardised critical appraisal tool (e.g., SURE collaboration checklist).

\section{Presentation and analysis}

- $\quad$ Populate a visual map with studies in appropriate cells. Maps can be online (e.g., grid with hyperlinks) and/or offline (e.g., Excel spreadsheet).

- A summary report may accompany the map, time and resources permitting.

Note. Adapted from Snilstveit et al., 2013. 


\section{Adolescent Well-Being Gap Maps}

Evidence Gap Maps typically map out empirical evidence from impact evaluations and systematic reviews, to highlight gaps in the evidence base and show where evidence is more abundant. In many cases, evidence maps also critically appraise systematic reviews, and rate the quality of the existing evidence. Evidence maps do not provide recommendations, or answer any specific research questions, but simply give a broad overview of the existing evidence. Map authors employ frameworks of policy-relevant interventions and outcomes that should encompass the range of interventions and outcomes covered by the map (Snilstveit et al., 2013). Typically, they will employ a protocol similar to that seen in Figure A1.

\section{Search Strategy for Maps}

This study is not a mapping activity but rather a broad analysis of the landscape of adolescent well-being evidence, as expressed through evidence maps. While a full systematic search will not be employed (due to constraints on time and resources), some systematic approaches will be used to ensure that all relevant evidence maps are identified.

A comparison of different approaches in evidence and gap mapping (Saran \& White, 2018) identified the main organisations that have produced evidence maps since the inception of the term in 2003. Additionally, International Initiative for Impact Evaluation \& The Centre of Excellence for Development, Impact and Learning (2017) highlighted that most evidence maps are found on website-based databases, and not in academic databases. Therefore, the search will start with the following organisations and their websites:

- Campbell Collaboration

- Collaboration for Environmental Evidence (CEE)

- Department of Veteran Affairs (Health Services Research and Development)

- Epistemonikos Foundation

- Evidence Based Policing Matrix (EBPM)

- Evidence for Policy and Practice Information and Co-ordinating Centre (EPPI-Centre)

- International Initiative for Impact Evaluation (3ie)

- International Rescue Committee (IRC)

- IZA Institute of study of Labour Economics, World of Labour (IZA)

- National Trauma Research Institute - Global Evidence Mapping Initiative (GEMI)

- Sightsavers

- The Social Care Institute for Excellence (SCIE)

- Yale Prevention Research 


\section{Adolescent Well-Being Gap Maps}

International Initiative for Impact Evaluation \& The Centre of Excellence for Development, Impact and Learning (2017) also identified additional website-based databases in its Map of Maps focusing specifically on mapping evidence maps from the LMIC region. These organisations and their websites will also be included in the search:

- Oxfam Humanitarian Evidence Programme

- South Africa Department of Planning, Monitoring and Evaluation (DPME)

- Swedish Agency for Health Technology Assessment and Assessment of Social Services (SBU)

- UK Department for International Development (DFID) (Research for Development Outputs)

- UNICEF Innocenti

- USAID

Given that no central repository for evidence maps exists, a broad Google search will also be conducted with the search strings, and the first 500 results will be screened.

Reference checking and forward citation-tracking of key literature on evidence mapping will also be conducted (e.g., Snilstveit et al., 2013; Snilstveit et al., 2016; International Initiative for Impact Evaluation \& The Centre of Excellence for Development, Impact and Learning, 2017), as well as seeking recommendations for maps and databases from the Steering Group.

The following search strings will be used (from International Initiative for Impact Evaluation \& The Centre of Excellence for Development, Impact and Learning, 2017, Map of Maps, p. 33 edited slightly from original):

"evidence map" OR "evidence maps" OR "evidence mapping" OR "evaluation map" OR "evaluation maps" OR "evaluation mapping" OR "evidence gap map" OR "evidence and gap map" OR "gap map"

(Note: Given that there is little consistency is the naming of evidence maps themselves, this search string takes a wide breadth and instead screens for evidence maps based on methodological criteria at the abstract or full-text stage.)

In addition to one general search for the methodology type (above), an adolescent-specific string will also be used as a modifier (from Bakrania et al., 2018, An evidence gap map on 


\section{Adolescent Well-Being Gap Maps}

adolescent well-being in low- and middle-income countries: A focus on the domains of protection, participation and financial and material well-being, Study protocol, p. 17):

adolescen* OR "young people" OR "young adult" OR youth OR teenager OR "young women" OR "young men" OR girl OR boy OR son OR daughter OR children OR "after school" "adolescen*" OR "young people" OR "young adult" OR "youth" OR "teenager" OR "young women" OR "young men" OR "girl" OR "boy" OR "son" OR "daughter" OR "children" OR "after school"

Adaptations to the search strings may be required depending on the technical capabilities of individual website-based databases. When the built-in search in a website appears inadequate, the Google operation to search within a single domain (e.g., "site:") will be used.

The publication period is 2003 until May 2019.

\section{Full Descriptions of Domains}

- Economic and financial well-being is among one of the more well-developed areas of research and relates to the capability of adolescents to secure, have, and use assets, and their participation in economic activities, including programs and policy interventions aimed at transitioning adolescents into decent jobs and productive livelihoods. This includes labour-related activities (e.g., employment, entrepreneurship, training, transferrable skills), accessing financial services and financial inclusion, and cash transfers (Commonwealth Secretariat, 2016; UNICEF, 2018).

- The education domain relates to knowledge and skills gained in formal education (i.e., classroom-based schooling provided by trained teachers), and academic outcomes such as educational achievement and school enrollment. It also includes non-formal or informal education (e.g., outside of the classroom, after-school programs, communitybased organizations, religious institutions), with outcomes that relate to life skills, and social or cultural development (UNESCO Institute for Statistics, 2012; UNICEF, 2018). Interventions that take place in school, but do not have a clear educational component, were not coded as education.

- The domain of empowerment and participation relates to interventions that promote or support adolescents voicing their needs and demands and asserting accountability for rights vis-à-vis decision makers at home, within their communities, or at different governance levels. It involves the exercise of freedom of expression and freedom of assembly and association, to organize collectively with peers. It also includes civic 


\section{Adolescent Well-Being Gap Maps}

participation and community development through leading or implementing initiatives (including peer-led programming) in civic spaces (e.g., through sport, religious groups, music, drama, the arts), volunteerism, and developing and exercising leadership skills (The Commonwealth, 2017; UNICEF, 2018). Mentorship programs and "safe spaces" that encourage free and open expression were included under this domain.

- The health and well-being domain include all elements relating to physical health and mental well-being of adolescents, including nutrition and medical care, sexual and reproductive health (including the health needs of teen mothers), access to water and sanitation, as well as infectious and non-communicable diseases, tobacco use, stress, and suicide. Interventions relating to psychosocial well-being were included, when relating to preventative or therapeutic interventions (The Commonwealth, 2017; UNICEF, 2018).

- Housing relates to the quality, safety, and availability of housing available to adolescents, including other shelter-related issues, such as access to and quality of electricity supply (European Youth Forum et al., 2017) This domain is of increasing interest as its estimated that $60 \%$ of all urban dwellers will be under the age of 18 by 2030 (UN-HABITAT, 2013).

- Information and Communications Technologies (ICT) are of significant importance as young people are at the forefront of technological adoption, with $70 \%$ of the world's youth online (International Telecommunication Union, 2017). This domain relates to the use of digital technologies, such as mobile phones, computers and other technologies, including the ability of adolescents to access and exchange information via telephone and/or internet, and access to information through a free press (European Youth Forum et al., 2017).

- Protection, safety, and security refers to interventions that promote a stable sense of physical safety and security among adolescents. Personal identity and bodily integrity are key aspects of the protection domain, along with the ability to have fulfilling and supportive relationships, to feel connected, and to be protected in their families, among their peers, in their schools, in their social and virtual environments, and in stable and peaceful communities and contexts. Positive parenting and parenting skills relates to this domain, as does out-of-home care (e.g., foster care, residential care). Includes protection from experiences prematurely, such as hazardous labour and teen marriage, and having access to legal support and fair judicial systems (juvenile justice) (UNICEF, 2018). Psychosocial support programs were included as part of this domain.

- A cross-cutting domain was also introduced, which includes interventions that could be relevant to all seven other domains, or conversely could not be associated with one 
domain in particular. At outcome component or study level, examples include broadbased social norms programming (without a specific target), or knowledge of available services for adolescents (without a specified sector).

\section{PROGRESS-Plus Schema, Definitions and Approach}

Coding schema developed using the PROGRESS-Plus approach are shown in Table A1.

\section{Table A1. PROGRESS-Plus Definitions}

\begin{tabular}{|c|c|}
\hline \multicolumn{2}{|l|}{ PROGRESS } \\
\hline Place of residence & Rural/urban, country/state, area deprivation, housing characteristics \\
\hline Ethnicity & Ethnic background \\
\hline Occupation & Professional, skilled, unskilled, unemployed, etc. \\
\hline Gender & Male or female \\
\hline Religion & Religious background \\
\hline Education & Years in and/or level of education attained, school type \\
\hline Social capitala & Neighborhood/community/family support \\
\hline Socio-economic status (SES) & $\begin{array}{l}\text { Income-related measure-e.g., means-tested benefits/welfare, } \\
\text { affluence measures, etc. }\end{array}$ \\
\hline \multicolumn{2}{|l|}{ Plus } \\
\hline "All SES" & $\begin{array}{l}\text { SES and other income-related measures of SEP::occupation, } \\
\text { education, elements of place of residence }\end{array}$ \\
\hline Age & Age range \\
\hline Disability & Existence of physical or emotional/mental disability \\
\hline Sexual Orientation & Heterosexual, gay, lesbian, bisexual, transgender \\
\hline $\begin{array}{l}\text { Other vulnerable and socially } \\
\text { excluded groups (review- } \\
\text { specific) }\end{array}$ & $\begin{array}{l}\text { School non-attenders, looked-after young people, young people in } \\
\text { the criminal justice system, victims of abuse, runaways, teenage } \\
\text { parents }\end{array}$ \\
\hline
\end{tabular}

Note. Adapted from Health promotion, inequalities and young people's health: A systematic review of research by S.

Oliver, J. Kavanagh, J. Caird, T. Lorenc, K. Oliver, A. Harden, A., J. Thomas, A. Greaves, and A. Oakley, 2008.

University of London, Social Science Research Unit, Institute of Education. EPPI-Centre.

a "Social capital" describes support available through informal social networks of neighborhoods, communities, and families; in relation to young people, we recognized social capital as largely related to family structure and the form and quality of family relationships. 


\section{Adolescent Well-Being Gap Maps}

A map, outcome component, or study was considered to employ an equity approach (Welch et al., 2019; Snilstveit et al., 2016) if one of the following three criteria were employed: (a) Assesses effects of interventions targeting disadvantaged or at-risk populations. Intervention may not have explicit equity outcomes but nonetheless provides evidence about reducing inequities. This was the most commonly employed equity approach in our analysis; (b) Assesses effects of interventions aimed at reducing social gradients across populations or among subgroups of the population; or (c) Assesses effects of interventions aimed at the general population, where it is important to understand the variations in outcomes across one or more PROGRESS-Plus characteristics. This employed more than just disaggregation by population but sought to look at underlying equity dimensions.

\section{Methodology and findings for map and outcome component level}

The steps for searching for and identifying maps and then applying screening criteria are depicted in Figure A2. 
Figure A2. Identifying Maps and Screening Outcomes

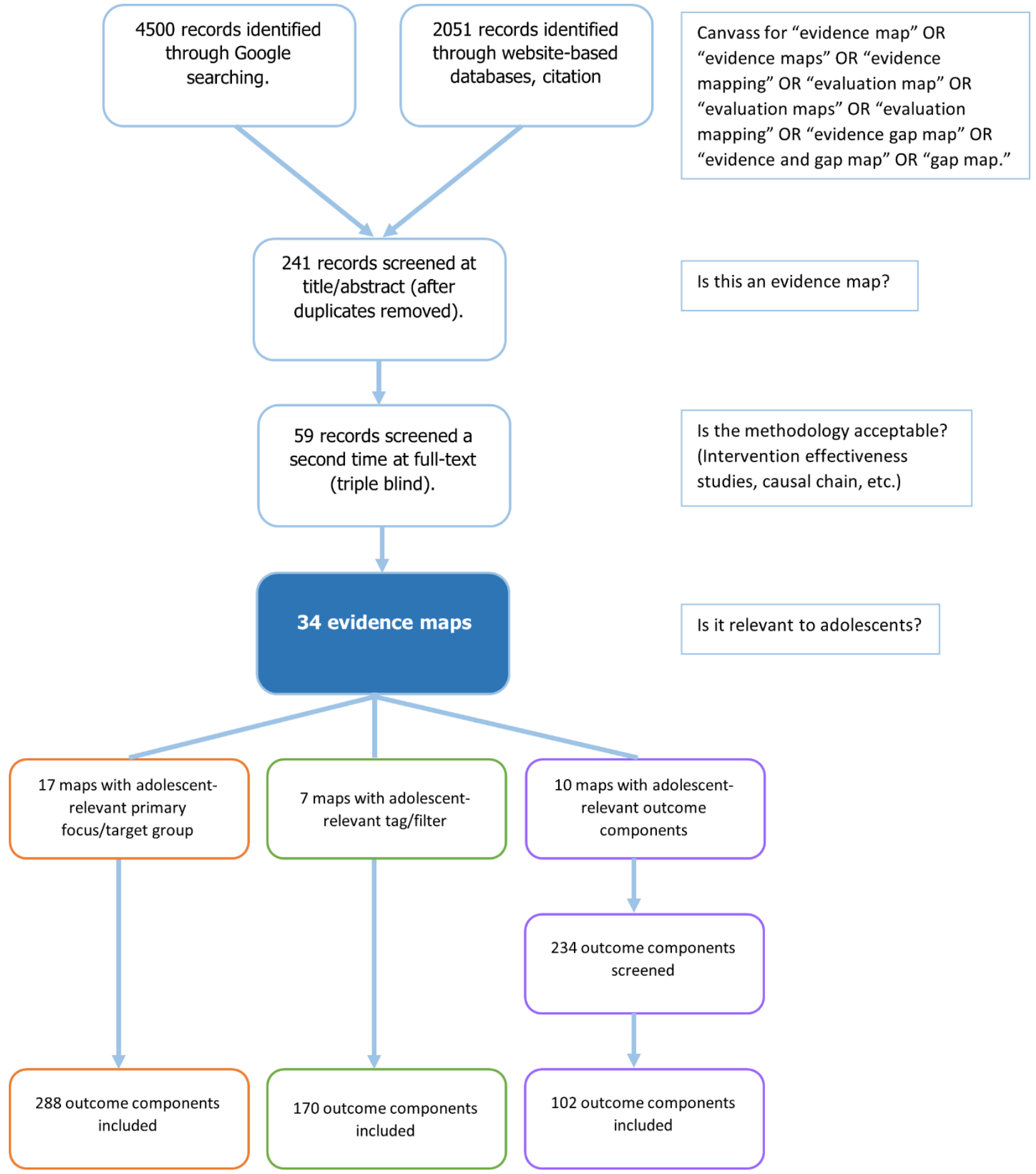




\section{Map and Outcome Component Findings}

Map Level Findings

Protection, safety, and security is the most popular domain covered by the evidence maps (35\%; $12 / 34$ maps), followed by education (24\%; 8/34 maps), then health (21\%; $7 / 34$ maps). In contrast, only $6 \%$ ( 2 out of 34 maps) cover ICT, while no maps cover housing. This is graphically presented in Figure A3.

Figure A3. Domain Focus of Evidence Maps

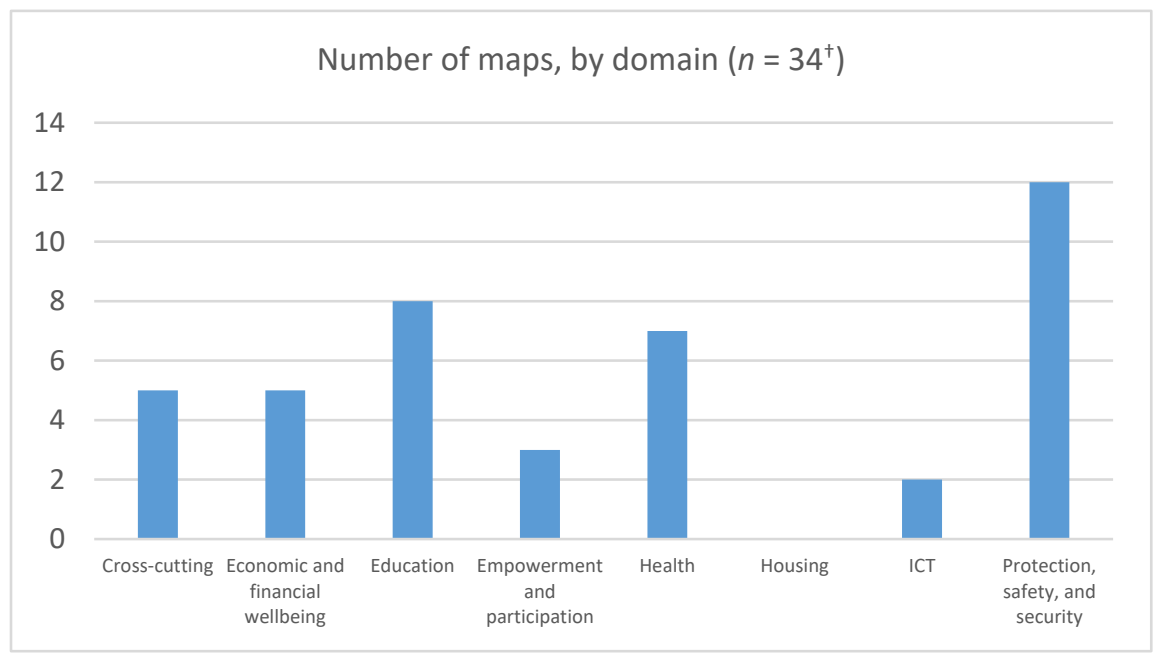

Note. ${ }^{\dagger}$ Double counting possible.

While $47 \%$ of maps (16/34 maps) are focused only on low- and middle-income countries, $35 \%$ (12/34 maps) have a global scope, and 18\% (6/34 maps) are focused only on high income settings. Adolescents are the primary focus or target group in 50\% of maps (17/34 maps); $29 \%$ (10/34 maps) include adolescents within their outcome components, and 21\% (7/34 maps) provide filter or tag options to capture adolescents.

As seen in Figure A4, evidence maps that cover the age ranges of middle (13-15 years old) and late (16-19 years old) adolescence are the most common (38\% each; $13 / 34$ maps). 29\% (10/34 maps) cover early adolescence (10-12 years old). Maps that are coded "unspecified" did not define a specific age range, while those that are "n/a" did not have a population focus, but rather a thematic focus (e.g., Cash Transfer Map, Economic Wellbeing Map). 
Figure A4: Age Focus of Evidence Maps

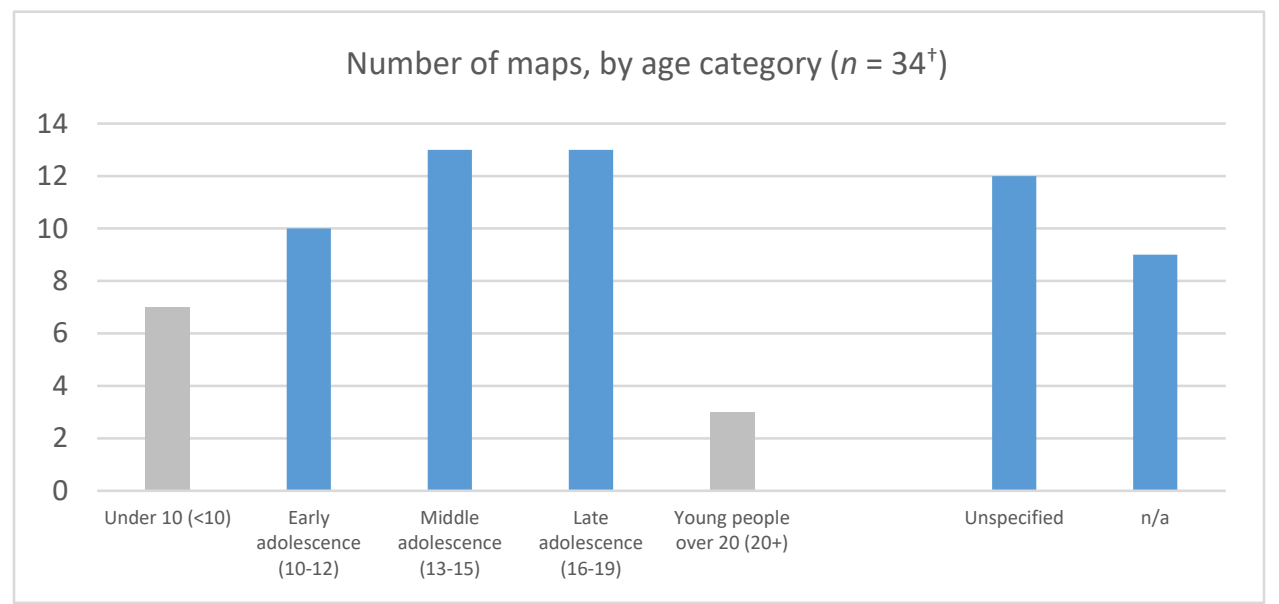

Note. ${ }^{\dagger}$ Double counting possible.

Nearly all maps (94\%; 32/34 maps) are engaged with some type of discussion around equityeither included as a main thematic focus, a focus through an outcome or intervention, or by analysis or filters. The distribution of dimensions of equity covered by the maps is presented in Figure A5. The challenge with using the PROGRESS-Plus equity categories can be seen in the use of the "Other" code, which was coded more than any other category (76\%; 26/34 maps). Populations included under "Other" included refugees, internally displaced persons (IDPs), people living in peri-urban areas, and young people in constrained democratic spaces. Gender and sex was the next most widely observed equity dimension covered by the maps (59\%; 20/34 maps), however despite being the most prevalent equity dimension observed, this is a troubling finding given the importance of gender considerations during adolescence. Gender is followed by disability (35\%; 12/34 maps). 
Figure A5: Equity Dimensions Included in Evidence Maps

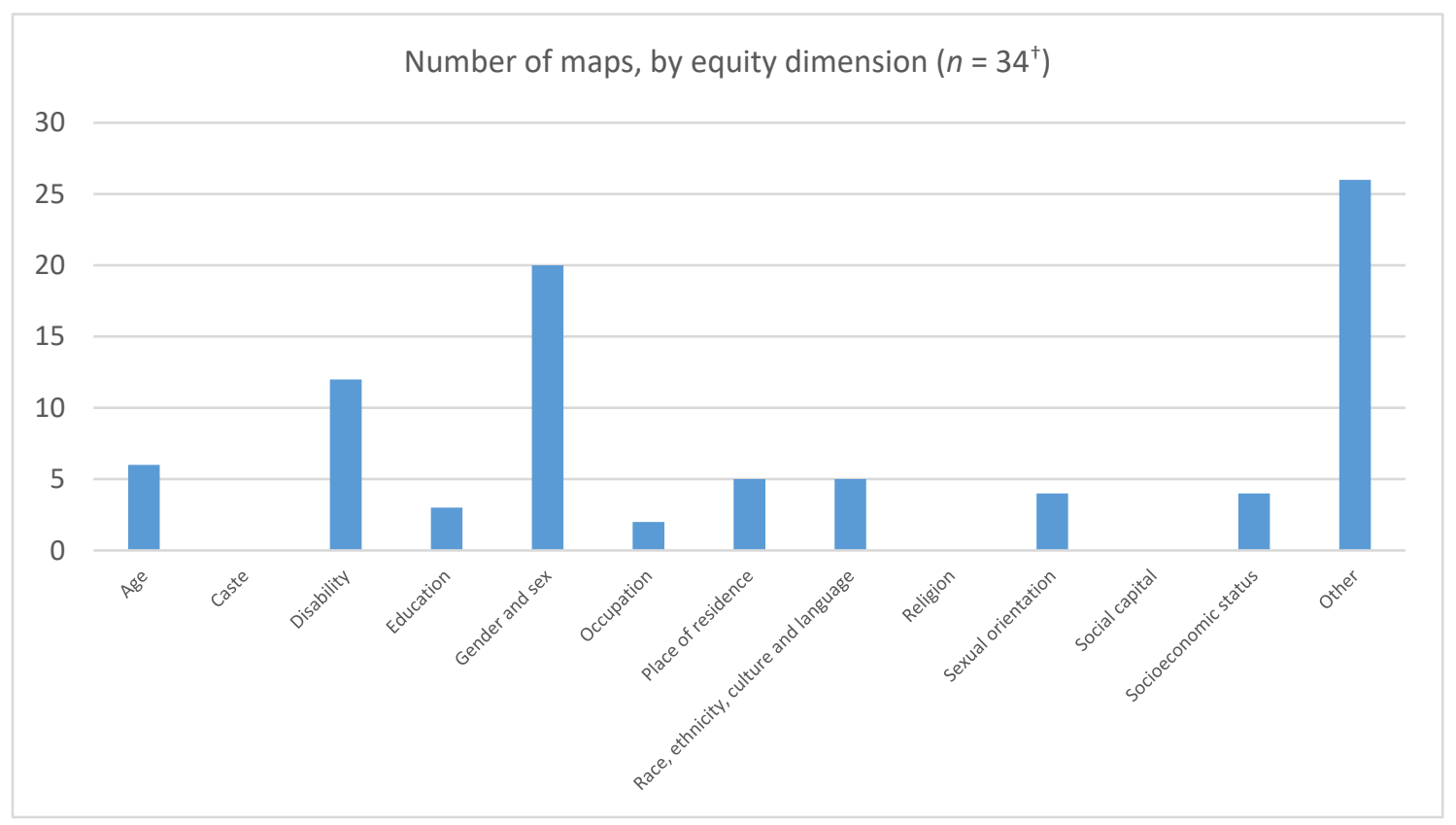

Note. ${ }^{\dagger}$ Double counting possible.

\section{Outcome Component Level Findings}

Outcomes in the health domain are the most widely observed (29\%; $165 / 560$ outcome components), followed by education (25\%; 140/560 outcome components) and protection, safety, and security (24\%; 135/560 outcome components). As shown in Figure A6, most outcomes are defined at the micro-level (76\%; 423/560 outcome components) focused at the individual or family level. By contrast, very few outcomes are defined at the macro level or in the policy space (3\%; 16/560 outcome components). 
Journal of Youth Development | http://jyd.pitt.edu/ | Vol. 16 Issue 2-3 DOI 10.5195/jyd.2021.1025

Adolescent Well-Being Gap Maps

Figure A6. Level of Focus of Outcome Components

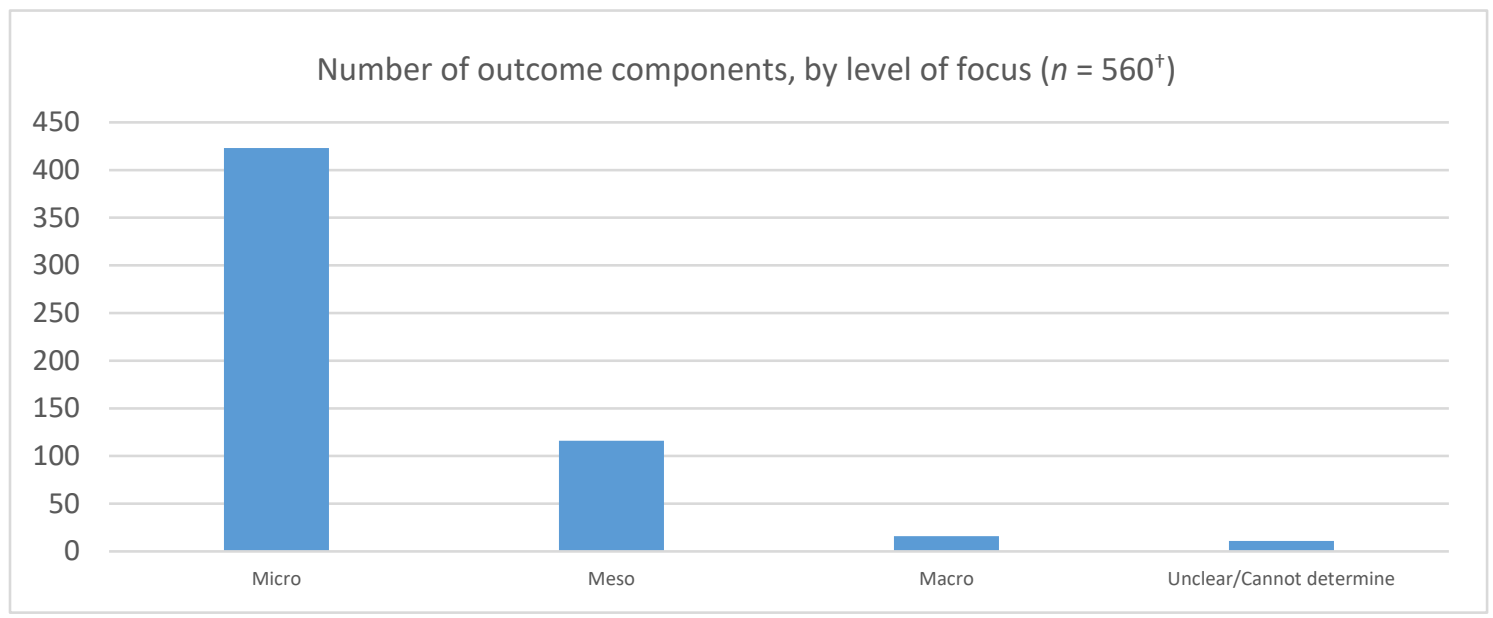

Note. ${ }^{\dagger}$ Double counting possible.

Information about the resulting 34 evidence maps is summarized in Table A2. Outcomes were generally concentrated within maps of the same theme, with a few exceptions. Maps focused on empowerment and participation tended to look at outcomes of the same theme, as well as those focused on protection, safety, and security, while maps focused on Information and Communication Technology (ICT) components were largely interested in education outcomes.

Table A2. List of Evidence Maps

\begin{tabular}{|c|c|}
\hline Title (Year) & $\begin{array}{l}\text { Citation } \\
\underline{\text { Website (if applicable) }}\end{array}$ \\
\hline $\begin{array}{l}\text { 1. Adolescent Sexual and } \\
\text { Reproductive Health } \\
\text { Evidence Gap Map } \\
\text { (2016) }\end{array}$ & $\begin{array}{l}\text { Rankin, K., Jarvis-Thiébault, J., Pfeifer, N., Engelbert, M., Perng, J., Yoon, } \\
\text { S., \& Heard, A. (2016). Adolescent sexual and reproductive health (3ie } \\
\text { Evidence Gap Map Report 5). International Initiative for Impact Evaluation } \\
\text { (3ie). } \\
\text { https://www.3ieimpact.org/evidence-hub/publications/evidence-gap- } \\
\text { maps/adolescent-sexual-and-reproductive-health-evidence-gap }\end{array}$ \\
\hline $\begin{array}{l}\text { 2. Cash Transfer Map } \\
\text { (2016) }\end{array}$ & $\begin{array}{l}\text { International Rescue Committee (IRC). (2016, September 19). Cash } \\
\text { transfer map. } \\
\text { https://www.rescue.org/resource/strategy-2020-outcomes-and-evidence- } \\
\text { framework-evidence-maps }\end{array}$ \\
\hline
\end{tabular}




\begin{tabular}{|c|c|}
\hline $\begin{array}{l}\text { 3. Children and Families } \\
\text { Evidence: Children with } \\
\text { disabilities (2017) }\end{array}$ & $\begin{array}{l}\text { Shlonsky, A., Albers, B., Taylor, D., Featherston, B., Ma, J., \& McCann, B. } \\
\text { (2017). Children and families evidence: Findings from six evidence gap } \\
\text { maps (Report for Victoria Department of Health and Human Services). } \\
\text { University of Melbourne. }\end{array}$ \\
\hline $\begin{array}{l}\text { 4. Children and Families } \\
\text { Evidence: Family } \\
\text { violence (2017) }\end{array}$ & $\begin{array}{l}\text { Shlonsky, A., Albers, B., Taylor, D., Featherston, B., Ma, J., \& McCann, B. } \\
\text { (2017). Children and families evidence: Findings from six evidence gap } \\
\text { maps (Report for Victoria Department of Health and Human Services). } \\
\text { University of Melbourne. }\end{array}$ \\
\hline $\begin{array}{l}\text { 5. Children and Families } \\
\text { Evidence: Interventions } \\
\text { for young people with } \\
\text { high risk behaviours } \\
\text { (2017) }\end{array}$ & $\begin{array}{l}\text { Shlonsky, A., Albers, B., Taylor, D., Featherston, B., Ma, J., \& McCann, B. } \\
\text { (2017). Children and families evidence: Findings from six evidence gap } \\
\text { maps (Report for Victoria Department of Health and Human Services). } \\
\text { University of Melbourne. }\end{array}$ \\
\hline $\begin{array}{l}\text { 6. Children and Families } \\
\text { Evidence: Out-of-home } \\
\text { care (2017) }\end{array}$ & $\begin{array}{l}\text { Shlonsky, A., Albers, B., Taylor, D., Featherston, B., Ma, J., \& McCann, B. } \\
\text { (2017). Children and families evidence: Findings from six evidence gap } \\
\text { maps (Report for Victoria Department of Health and Human Services). } \\
\text { University of Melbourne. }\end{array}$ \\
\hline $\begin{array}{l}\text { 7. Children and Families } \\
\text { Evidence: Services for } \\
\text { Aboriginal children and } \\
\text { families (2017) }\end{array}$ & $\begin{array}{l}\text { Shlonsky, A., Albers, B., Taylor, D., Featherston, B., Ma, J., \& McCann, B. } \\
\text { (2017). Children and families evidence: Findings from six evidence gap } \\
\text { maps (Report for Victoria Department of Health and Human Services). } \\
\text { University of Melbourne. }\end{array}$ \\
\hline $\begin{array}{l}\text { 8. Children and Families } \\
\text { Evidence: Trauma- } \\
\text { informed services } \\
\text { (2017) }\end{array}$ & $\begin{array}{l}\text { Shlonsky, A., Albers, B., Taylor, D., Featherston, B., Ma, J., \& McCann, B. } \\
\text { (2017). Children and families evidence: Findings from six evidence gap } \\
\text { maps (Report for Victoria Department of Health and Human Services). } \\
\text { University of Melbourne. }\end{array}$ \\
\hline $\begin{array}{l}\text { 9. Economic Wellbeing } \\
\text { Map (2016) }\end{array}$ & $\begin{array}{l}\text { International Rescue Committee (IRC). (2016). Economic wellbeing map. } \\
\text { https://www.rescue.org/resource/strategy-2020-outcomes-and-evidence- } \\
\text { framework-evidence-maps }\end{array}$ \\
\hline $\begin{array}{l}\text { 10. Education in Crisis and } \\
\text { Conflict Network's } \\
\text { (ECCN's): External } \\
\text { Threats Safer Learning }\end{array}$ & $\begin{array}{l}\text { U.S. Agency for International Development (USAID). (2018). External } \\
\text { threats safer learning environments (SLE) gap map. USAID Education in } \\
\text { Crisis and Conflict Network (ECCN). }\end{array}$ \\
\hline $\begin{array}{l}\text { Environments (SLE) } \\
\text { Gap Map (2018) }\end{array}$ & $\begin{array}{l}\text { https://eccnetwork.net/resources/evidence-gap-maps/external-threats-sle- } \\
\text { gap-map/ }\end{array}$ \\
\hline
\end{tabular}


Journal of Youth Development | http://jyd.pitt.edu/ | Vol. 16 Issue 2-3 DOI 10.5195/jyd.2021.1025

Adolescent Well-Being Gap Maps

\begin{tabular}{|c|c|}
\hline $\begin{array}{l}\text { 11. Education in Crisis and } \\
\text { Conflict Network's } \\
\text { (ECCN's): Health- } \\
\text { Related Threats Safer } \\
\text { Learning Environments } \\
\text { (SLE) Gap Map (2019) }\end{array}$ & $\begin{array}{l}\text { U.S. Agency for International Development (USAID). (2019). Health- } \\
\text { related threats safer learning environments (SLE) gap map. USAID } \\
\text { Education in Crisis and Conflict Network (ECCN). }\end{array}$ \\
\hline $\begin{array}{l}\text { 12. Education in Crisis and } \\
\text { Conflict Network's } \\
\text { (ECCN's): Internal } \\
\text { Threats Safer Learning } \\
\text { Environments (SLE) } \\
\text { Gap Map (2019) }\end{array}$ & $\begin{array}{l}\text { U.S. Agency for International Development (USAID). (2019). Internal } \\
\text { threats safer learning environments (SLE) gap map. USAID Education in } \\
\text { Crisis and Conflict Network (ECCN). }\end{array}$ \\
\hline $\begin{array}{l}\text { 13. Education in Crisis and } \\
\text { Conflict Network's } \\
\text { (ECCN's): Natural } \\
\text { Disasters Safer } \\
\text { Learning Environments } \\
\text { (SLE) Gap Map (2017) }\end{array}$ & $\begin{array}{l}\text { U.S. Agency for International Development (USAID). (2017). Natural } \\
\text { disasters safer learning environments (SLE) gap map. USAID Education in } \\
\text { Crisis and Conflict Network (ECCN). } \\
\text { https://eccnetwork.net/resources/evidence-gap-maps/nat-disasters-sle- } \\
\text { gap-map/ }\end{array}$ \\
\hline 14. Education & $\begin{array}{l}\text { International Rescue Committee (IRC). (2016). Education map. } \\
\text { https://www.rescue.org/resource/strategy-2020-outcomes-and-evidence- } \\
\text { framework-evidence-maps }\end{array}$ \\
\hline $\begin{array}{l}\text { 15. Education Technology } \\
\text { Evidence Map (2016) }\end{array}$ & $\begin{array}{l}\text { Muyoya, C., Brugha, M., \& Hollow, D. (2016). Education technology map: } \\
\text { Guidance document and evidence map. Jigsaw Consult. } \\
\text { https://www.gov.uk/dfid-research-outputs/education-technology-evidence- } \\
\underline{\text { map }}\end{array}$ \\
\hline $\begin{array}{l}\text { 16. eHealth for HIV } \\
\text { prevention, diagnosis, } \\
\text { treatment and care for } \\
\text { key populations and } \\
\text { young people } \\
\text { worldwide (2018) }\end{array}$ & $\begin{array}{l}\text { Frontline AIDS, International HIV/AIDS Alliance, \& Africa Centre for } \\
\text { Evidence at the University of Johannesburg. (2018). eHealth interventions } \\
\text { for HIV prevention, diagnosis, treatment and care for key populations and } \\
\text { young people worldwide: Systematic evidence map. } \\
\text { https://frontlineaids.org/resources/systematic-evidence-map-ehealth-for- } \\
\text { key-populations-and-young-people }\end{array}$ \\
\hline
\end{tabular}


Journal of Youth Development | http://jyd.pitt.edu/ | Vol. 16 Issue 2-3 DOI 10.5195/jyd.2021.1025

Adolescent Well-Being Gap Maps

\begin{tabular}{|c|c|}
\hline $\begin{array}{l}\text { 17. Evidence and Gap Map } \\
\text { of Studies assessing } \\
\text { the Effectiveness of } \\
\text { Interventions for } \\
\text { people with Disabilities } \\
\text { (2018) }\end{array}$ & $\begin{array}{l}\text { White, H., Saran, A., \& Kuper, H. (2018). Evidence and gap map of studies } \\
\text { assessing the effectiveness of interventions for people with disabilities } \\
\text { (CEDIL Inception Paper 12). CEDIL. } \\
\underline{\text { https://www.gov.uk/dfid-research-outputs/evidence-and-gap-map-of- }} \\
\underline{\text { studies-assessing-the-effectiveness-of-interventions-for-people-with- }} \\
\underline{\text { disabilities }}\end{array}$ \\
\hline $\begin{array}{l}\text { 18. Evidence for } \\
\text { Peacebuilding } \\
\text { Evidence Gap Map } \\
\text { (2015) }\end{array}$ & $\begin{array}{l}\text { Cameron, D., Brown, A., Mishra, A., Picon, M., Esper, H., Calvo, F., \& } \\
\text { Peterson, K. (2015). Evidence for peacebuilding: An evidence gap map. } \\
\text { International Initiative for Impact Evaluation (3ie). } \\
\text { https://www.3ieimpact.org/evidence-hub/publications/evidence-gap- } \\
\text { maps/evidence-peacebuilding-evidence-gap-map }\end{array}$ \\
\hline $\begin{array}{l}\text { 19. Evidence Gap Map on } \\
\text { adolescent well-being } \\
\text { in low- and middle- } \\
\text { income countries: } \\
\text { Protection, } \\
\text { Participation and } \\
\text { Financial and Material } \\
\text { Well-being (2018) }\end{array}$ & $\begin{array}{l}\text { Bakrania, S., Ghimire, A., \& Blavin, N. (2018). Bridging the gap to } \\
\text { understand effective interventions for adolescent well-being: An evidence } \\
\text { gap map on protection, participation and financial and material well-being } \\
\text { in low- and middle-income countries. UNICEF Office of Research - } \\
\text { Innocenti. }\end{array}$ \\
\hline $\begin{array}{l}\text { 20. Frontline AIDS map of } \\
\text { community action on } \\
\text { HIV, health and rights } \\
\text { (2019) }\end{array}$ & $\begin{array}{l}\text { Institute of Development Studies and We are Potential. (2019). Evidence } \\
\text { map of community action on HIV, health and rights. } \\
\text { https://frontlineaids.org/resources/evidence-map-community-action-hiv- } \\
\text { health-rights/ }\end{array}$ \\
\hline $\begin{array}{l}\text { 21. Girls' clubs, life skills } \\
\text { programmes and girls' } \\
\text { well-being outcomes }\end{array}$ & $\begin{array}{l}\text { Marcus, R., Gupta-Archer, N., Darcy, M., \& Page, E. (2017). Girls' clubs, } \\
\text { life skills programmes and girls' well-being outcomes (GAGE Rigorous } \\
\text { Review). Overseas Development Institute. } \\
\text { https://www.gage.odi.org/publication/rigorous-review-girls-clubs-life-skills- } \\
\text { programmes/ }\end{array}$ \\
\hline $\begin{array}{l}\text { 22. Group-based } \\
\text { Livelihood } \\
\text { Interventions in } \\
\text { L\&MICs (2019) }\end{array}$ & $\begin{array}{l}\text { Barooah, B., Chinoy, S.L., Dubey, P., Sarkar, R., Bagai, A., \& Rathinam, F. } \\
\text { (2019). Improving and sustaining livelihoods through group-based } \\
\text { interventions: mapping the evidence (3ie Evidence Gap Map Report 13). } \\
\text { International Initiative for Impact Evaluation (3ie). }\end{array}$ \\
\hline
\end{tabular}


Journal of Youth Development | http://jyd.pitt.edu/ | Vol. 16 Issue 2-3 DOI 10.5195/jyd.2021.1025

Adolescent Well-Being Gap Maps

\begin{tabular}{|c|c|}
\hline & $\begin{array}{l}\text { http://gapmaps.3ieimpact.org/evidence-maps/group-based-livelihood- } \\
\text { interventions-Imics }\end{array}$ \\
\hline 23. Health Map (2016) & $\begin{array}{l}\text { International Rescue Committee (IRC). (2016). Health map. } \\
\text { https://www.rescue.org/resource/strategy-2020-outcomes-and-evidence- } \\
\text { framework-evidence-maps }\end{array}$ \\
\hline $\begin{array}{l}\text { 24. Homelessness } \\
\text { evidence and gap map } \\
\text { (2018) }\end{array}$ & $\begin{array}{l}\text { White, H. (2018). Evidence and gap maps on homelessness: A launch pad } \\
\text { for strategic evidence production and use. Center for Homelessness } \\
\text { Impact. } \\
\text { https://www.homelessnessimpact.org/post/announcing-evidence-and-gap- } \\
\underline{\text { maps }}\end{array}$ \\
\hline $\begin{array}{l}\text { 25. Humanitarian } \\
\text { Emergencies Map } \\
\text { (2016) }\end{array}$ & $\begin{array}{l}\text { International Rescue Committee (IRC). (2016). Humanitarian emergencies } \\
\text { map. } \\
\text { https://www.rescue.org/resource/strategy-2020-outcomes-and-evidence- } \\
\text { framework-evidence-maps }\end{array}$ \\
\hline $\begin{array}{l}\text { 26. Modern slavery } \\
\text { prevention and } \\
\text { responses in South } \\
\text { Asia: An evidence map } \\
\text { (2018) }\end{array}$ & $\begin{array}{l}\text { Oosterhoff, P., Yunus, R., Jensen, C., Somerwell, F., \& Pocock, N. (2018). } \\
\text { Modern slavery prevention and responses in South Asia: An evidence map. } \\
\text { Department for International Development. } \\
\text { https://www.gov.uk/dfid-research-outputs/modern-slavery-prevention- } \\
\text { and-responses-in-south-asia-an-evidence-map }\end{array}$ \\
\hline $\begin{array}{l}\text { 27. Primary and Secondary } \\
\text { Education Evidence } \\
\text { Gap Map (2019) }\end{array}$ & $\begin{array}{l}\text { International Initiative for Impact Evaluation (3ie) (2016). Primary and } \\
\text { secondary education evidence gap map. } \\
\text { http://gapmaps.3ieimpact.org/evidence-maps/primary-and-secondary- } \\
\text { education-evidence-gap-map }\end{array}$ \\
\hline $\begin{array}{l}\text { 28. Psychosocial function } \\
\text { and health in veteran } \\
\text { families (2015) }\end{array}$ & $\begin{array}{l}\text { Jensen, M. T., Karmsteen, K., Jorgensen, A. K., \& Rayce, S. B. (2015). } \\
\text { Psychosocial function and health in veteran families: A gap map of } \\
\text { publications within the field. } \\
\text { https://pure.vive.dk/ws/files/292394/1537 Psychosocial function and he } \\
\text { alth_in veteran families.pdf }\end{array}$ \\
\hline
\end{tabular}


Journal of Youth Development | http://jyd.pitt.edu/ | Vol. 16 Issue 2-3 DOI 10.5195/jyd.2021.1025

Adolescent Well-Being Gap Maps

\begin{tabular}{|c|c|}
\hline 29. Safety Map (2016) & $\begin{array}{l}\text { International Rescue Committee (IRC). (2016). Safety map. } \\
\text { https://www.rescue.org/resource/strategy-2020-outcomes-and-evidence- } \\
\text { framework-evidence-maps }\end{array}$ \\
\hline $\begin{array}{l}\text { 30. Service Delivery Map } \\
\text { (2016) }\end{array}$ & $\begin{array}{l}\text { International Rescue Committee (IRC). (2016). Service delivery map. } \\
\text { https://www.rescue.org/resource/strategy-2020-outcomes-and-evidence- } \\
\text { framework-evidence-maps }\end{array}$ \\
\hline $\begin{array}{l}\text { 31. Water, Sanitation, and } \\
\text { Hygiene (WASH) } \\
\text { Evidence Gap Map: } \\
2018 \text { update (2018) }\end{array}$ & $\begin{array}{l}\text { International Initiative for Impact Evaluation (3ie) (2018). Water, } \\
\text { sanitation, and hygiene evidence gap map: } 2018 \text { update. } \\
\text { http://gapmaps.3ieimpact.org/evidence-maps/water-sanitation-and- } \\
\text { hygiene-wash-evidence-gap-map-2018-update }\end{array}$ \\
\hline $\begin{array}{l}\text { 32. Young people as } \\
\text { agents and advocates } \\
\text { of development (2016) }\end{array}$ & $\begin{array}{l}\text { Marcus, R., \& Cunningham, A. (2016). Young people as agents and } \\
\text { advocates of development: Evidence gap map report. Overseas } \\
\text { Development Institute. } \\
\text { https://www.odi.org/publications/10653-young-people-agents-and- } \\
\text { advocates-development }\end{array}$ \\
\hline $\begin{array}{l}\text { 33. Youth \& Transferable } \\
\text { Skills Evidence Gap } \\
\text { Map (2015) }\end{array}$ & $\begin{array}{l}\text { Rankin, K., Cameron, D. B., Ingraham, K., Mishra, A., Burke, J., Picon, M., } \\
\text { Miranda, J., \& Brown, A. N. (2015). Youth and transferable skills: an } \\
\text { evidence gap map (3ie Evidence Gap Report 2). International Initiative for } \\
\text { Impact Evaluation (3ie). } \\
\text { http://gapmaps.3ieimpact.org/evidence-maps/youth-transferable-skills- } \\
\text { evidence-gap-map }\end{array}$ \\
\hline $\begin{array}{l}\text { 34. Youth Employment } \\
\text { Evidence Gap Map } \\
\text { (2017) }\end{array}$ & $\begin{array}{l}\text { International Labour Organization (ILO). (2017). Youth employment } \\
\text { evidence gap map. } \\
\text { http://gapmaps.3ieimpact.org/evidence-maps/youth-employment- } \\
\text { evidence-gap-map }\end{array}$ \\
\hline
\end{tabular}

